Portland State University

PDXScholar

6-8-2021

\title{
Open Crime Maps: How Are Police Departments Doing So Far?
}

Khaing Sandee Lynn

Portland State University

Follow this and additional works at: https://pdxscholar.library.pdx.edu/open_access_etds

Part of the Criminology Commons

Let us know how access to this document benefits you.

\section{Recommended Citation}

Lynn, Khaing Sandee, "Open Crime Maps: How Are Police Departments Doing So Far?" (2021).

Dissertations and Theses. Paper 5717.

https://doi.org/10.15760/etd.7590

This Thesis is brought to you for free and open access. It has been accepted for inclusion in Dissertations and Theses by an authorized administrator of PDXScholar. Please contact us if we can make this document more accessible: pdxscholar@pdx.edu. 
Open Crime Maps: How Are Police Departments Doing So Far?

by

Khaing Sandee Lynn

A thesis submitted in partial fulfillment of the requirements for the degree of

\author{
Master of Science \\ in \\ Criminology and Criminal Justice
}

Thesis Committee:

Kris Henning, Chair

Kathryn Wuschke

Christopher Campbell

Portland State University

2021 
Abstract

In recent years, some police departments have started providing open crime maps depicting select crime-related data. However, there has been no studies so far evaluating map delivery sources, the type of maps delivered, and why agencies might be doing so. Using a random, stratified sample of 1,677 police departments from the 2013 Law Enforcement Management and Administrative Statistics (LEMAS) survey, the current study examines how many police departments provide access to online crime maps as well as how they are delivered (externally or internally) and prevalent map types (dot, density, choropleth, etc.). Furthermore, whether or not agencies provided a justification(s) and/or explanation(s) associated with the displayed data were documented. The study found crime map availability increased over time, with most of them delivered externally and in the form of dot maps. Findings suggested that larger agencies, those with stronger commitment to community policing, higher website engagement, and higher social media use were more likely to deliver maps on their websites $(p<.001)$. However, despite the widespread and increasing use of open crime maps, very few agencies offered justifications for such practices, and even fewer provided explanations concerning the maps themselves and mapped crime-related data. 
Table of Contents

Abstract.............................................................

List of Tables.......................................................

List of Figures................................................. iv

Chapter 1

Introduction.......................................................... 1

Chapter 2

Literature Review................................................. 3

Chapter 3

Methodology $\ldots \ldots \ldots \ldots \ldots \ldots \ldots \ldots \ldots \ldots \ldots \ldots \ldots \ldots \ldots \ldots \ldots \ldots \ldots \ldots \ldots \ldots \ldots, \quad 22$

Chapter 4

Results........................................................... 38

Chapter 5

Discussion...................................................... 46

Chapter 6

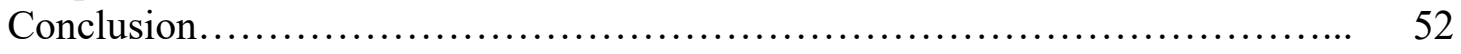

References......................................................... 54

Appendix A. Map Justification Review................................. 66

Appendix B. Metadata Review......................................... 66 
List of Tables

Tables Page

1. Bivariate Analyses of Characteristic and 2020 Map Availability.... 40

2. Regression Analyses for Agency Characteristics................ 41

3. Proportion of Agencies Providing Metadata..................... 46 
List of Figures

Figures Page

1. Rochester PD Crime Map Link............................. 33

2. Saint Petersburg PD Crime Map Link....................... 33 
Open Crime Maps: How Are Police Departments Doing So Far?

A map says to you, "Read me carefully, follow me closely, doubt me not...I am the earth in the palm of your hand." (Harley, 1989, p. 1, as cited in Graham \& Zook, 2011, p. 116)

Decades of the United States (US) government mishandling state and national affairs has left the American public in a state of deep cynicism and lack of trust towards the government (Coglianese, 2009). In recent years, due to a combination of concerns for government transparency and police treatment towards minority population, the public's distrust slowly spread to all government operations, including law enforcement ("The History of American Police Brutality", 2020). As a step towards eliminating such distrust and cynicism towards government, President Obama, in 2009, called for increased transparency by governmental agencies (Coglianese, 2009), including police organizations. Since then, police agencies have responded using two methods: 1 . by placing heavier emphasis on community policing values, and 2 . by sharing policingrelated data with the public using various methods, one of which is crime maps.

Maps have been used to represent material places and the transformations that occur within them over time (Graham \& Zook, 2011). Criminology literature has consistently indicated that crime is geographically influenced and shifts across time and place (Braga et al., 2019). Therefore, crime maps naturally are considered effective tools in depicting crime data and visualizing crime control efforts. Crime maps have been widely utilized within police agencies as tools to aid in crime analysis, prevention, and dispatch. In recent years, advancements in technology (Wartell \& McEwen, 2001), along 
with a push for open data sharing, have prompted police agencies to begin providing publicly accessible crime maps (Caplan et al., 2015).

Intra-agency uses of crime maps can be extended to the public with the provision of open crime maps. Similar to how crime maps aid police in identifying hot spots and even predict future crime locations, they can be used to inform the public of geographically based risks so that they can take precautions and lower likelihood of victimization (Wartell \& McEwen, 2001). However, experts of geography have warned that maps, similar to all other products of human intellect, can be altered at their creators' will and influence public perception of areas and populations depending on the manner in which they are generated and presented (Bednarz et al., 2006). Applying this notion to open crime maps, especially high-crime areas, the people residing within or near them, and their local police could become negatively viewed by outsiders if viewers do not entirely comprehend the mapped content and what the maps were meant to convey.

In short, crime maps are effective tools to convey crime-related information. For this reason, police agencies have started to provide public access to crime maps. However, limited research has examined the prevalence of these maps, the purposes behind their delivery to such a wide audience, and whether or not agencies have accounted for concerns raised by cartographic experts associated with this practice. Therefore, the current study evaluates crime map availability on police department (PD) websites in the US, along with the map type (e.g. dot, density, choropleth) and how they are being delivered (i.e. internally, externally via a third-party vendor, or both). The study further explored agency characteristics and their potential associations with PD likelihood to provide maps. Lastly, it evaluated whether or not PDs offer justifications (e.g. risk 
communication, trust-building, transparency, etc.) and explanations (e.g. how the map was generated, is being maintained, presented, etc.) for providing open crime maps to the public.

\section{Literature Review}

Cynicism and distrust of government has long existed in the hearts of the American people (in some more than others), fueled by each domestic or foreign affair their government mishandles, settling as time passes and memories fade, only to be stirred up again by another new issue that a new administration again mismanages. A well-known event in the 1950s - the civil rights movement - will serve as the first example. Decades-long campaigns to end institutionalized racial discrimination and racial segregation in the US led to anti-discrimination laws (part of the Civil Rights Act) passed, equalizing social, political, and economic rights of African Americans to those of whites - at least on paper. Skepticism rose when the public began to realize these laws and bills were not being translated to practice, due to failure of legislators in addressing "the accumulated gains of past discrimination" and rendering these new statues almost futile (Kendi, 2017).

Another major event that fueled public negative perceptions towards government and a divide of the American people was the Vietnam War during the presidency of Lyndon B. Johnson (McMahon, 2002). The US government operated in secrecy at first but began to show more solid support for South Vietnam troops later in their fight against communist North Vietnam - an undertaking that the American public strongly opposed for moral reasons such as meddling with Vietnamese independence, interfering in a 
foreign civil war, and deploying American troops to fight a clearly unwinnable war (Schreiber, 1973). Similarly, the Bush Administration launched the "War on Terror" in response to the September 11 terrorist attacks in 2001. This war authorized the invasion of Afghanistan and involved deploying thousands of US soldiers to fight yet another war without an end in sight. Again, the public expressed strong opposition for reasons similar to why it opposed US intervention in the Vietnam War in 1955 (Daalder \& Lindsay, 2001).

Decades of continued government operations domestically and internationally despite opposition from the public left the American public in a state of deep cynicism and mistrust (Coglianese, 2009). Slowly, heightened concerns of governmental secrecy and lack of transparency had extended to all government operations. The underlying mistrust of government, strengthened by documented, well-publicized incidents of police brutality against disadvantaged, minority populations since the 1960s ("The History of American Police Brutality”, 2020; Adams et al., 1999), heightened social concerns regarding policing, even causing some to distrust the law and individuals enforcing it (Hitchens et al., 2018). More commonly known as legal cynicism, this was a trend of distrust towards government that President Barrack Obama aimed to reverse by "creating an unprecedented level of open in Government." (2009, as cited in Coglianese, 2009). In the context of policing, it involved placing heavier emphasis on community policing values and sharing policing- and crime-related data with the public, both of which should enhance police legitimacy and public trust towards police.

Since the 1900s, more and more agencies have been claiming to incorporate community policing principles into practice, whether they may be crime reduction and 
prevention efforts, solving local problems, or fostering better relationships with the communities they serve (Maguire \& Mastrofski, 2000). A complex term to define, Friedmann (1992) described community policing to be traditional policing strategies supplemented by "a proactive reliance on community resources", "greater public share in decision-making," and "greater concern for civil rights and liberties.” (p. 2) Together, they should contribute to effective crime control, reduced fear of victimization, better quality of life, and improved police services, and trust towards police by the public.

With past research indicating that police legitimacy and public trust towards police heavily impact compliance with authority (Tyler, 2003), it is reasonable to be concerned about whether or not the perceived nature of policing foster negative attitudes among citizens. In addition, public willingness to accept and cooperate with legal authorities have been found to stem from evaluations of procedural justice (i.e. fairness in decision-making processes and treatment toward citizens), a relationship mediated by negative emotions (Murphy \& Tyler, 2008; Barkworth \& Murphy, 2018). In other words, an individual who experienced or is experiencing unfair treatment by police is less likely to comply, partly due to negative emotions such as anger that build during the treatment. Therefore, collective evaluations of encounters with police officers should positively or negatively impact willingness to comply, which, in turn, impact police legitimacy and trust towards police (Tyler, 2003).

Heightened social concerns, along with increased recognition of value of trust and legitimacy, have led to a recent push for law enforcement to share data with the public for enhanced openness. Open access to government information, a key component of government transparency, has been shown to positively contribute to police-community 
relationships (Redford, 1969, as cited in Piotrowski \& Van Ryzin, 2007). As an example, police departments in the United Kingdom (UK) have been publishing crime data on their websites since 2008 for the purposes of building trust and improving legitimacy (Chainey \& Tompson, 2012; Tompson et al., 2015). In the US, the 2015 President's Task Force on $21^{\text {st }}$ Century Policing presented suggestions on how PDs can accomplish crime reduction while building legitimacy and public trust. Doing so should positively contribute to greater public compliance with the law and cooperation with law enforcement (e.g. reporting crimes, testifying in criminal cases, etc.) (Tyler, 2003). A step toward open data sharing, in May 2015, the Obama administration introduced the Police Data Initiative (PDI) - a program which encouraged various stakeholders working towards increased use of data and technology by police in building community trust (Caplan et al., 2015). As a result, most government agencies, including police departments, now release data in machine-readable and computable formats. This open information provided by PDs include administrative data, arrest and criminal incident statistics, calls for service (CFS), use of force, and sex offender registry data. (Caplan et al., 2015). In addition to delivering raw data and crime statistics, some PDs are making online crime maps available. Such information sharing by the police may have additional advantages beyond trust and legitimacy.

In addition to responding to public demand for increased government transparency, certain characteristics of agencies may explain why they deliver open crime maps. One of these is an agency's commitment to community policing. A unique aspect of community policing is its heavy reliance on public cooperation, making crime control a partnership effort supported by both police and community members. For such efforts 
to be successful, efficient communication channels and awareness of police activity between agencies and citizens are necessary (Cohn, 1996). Recognizing the need for cooperation from community members may have led agencies to increase communication of crime- and policing-related information, and the development of crime maps may have followed shortly in this regard. Residents may find that publicly accessible crime data and maps allow for assessment of personal risk of victimization and may, in turn, take additional precautions to mitigate this risk.

In relation, the author discusses two well-known criminological theories to guide this research. Cohen and Felson's (1979) routine activities theory (RAT) suggests that most crime is geographically based and occurs when a likely offender encounters a suitable target in the absence of a capable guardian. By concentrating on the circumstances in which criminals commit crime, RAT posits that crime occurs when there is a convergence in space and time. As an example, a lone purse (i.e. a suitable target) sits on a restaurant table, and its owner (the capable guardian) does not seem to be in the proximity. Although the restaurant is situated in an area with heavy foot traffic, no one seemed to notice the unguarded purse except for one person (the likely offender) who was in need of money and was willing to pickpocket or steal. Due to the convergence in circumstances - i.e. a thief noticed an unguarded purse without an owner nearby - a theft can be committed as opposed to if there had been no purse, if the purse had been guarded, or the offender had not been in the proximity of the restaurant.

The second theory is crime pattern theory by Brantingham and Brantingham (1984). Crime pattern theory suggests that crime does not occur randomly throughout space. Instead, it tends to cluster, and the manner in which it does seems to be greatly 
influenced by where people live and how and why they move about between areas they frequent. These location networks can also be applied to criminals and their crime locations. When considering crime locations, it is important to recognize the patterns of an individual offender's movement, his/her network of friends who engage in criminal activities and where they reside or operate, potential locations of stationary targets he/she might target, and the travel patterns of his or her targets or victims. For example, an offender may loiter near a dimly lit area of a city part and frequently rob passersby, making that certain area a robbery hotspot in the park. In this case, the space within which the offender operates, and the victims' travel path overlapped. Crime occurred as a result.

According to both theories, crime therefore should be preventable through behavioral change (Clarke, 1995). In support, past literature has found positive associations between availability of open crime data and public perception of neighborhood safety and police (Chainey \& Tompson, 2012). Even if such practices do not entirely prevent crime, they very likely decrease the likelihood of an offender to be successful in the commission of crime. Effective crime risk communication has also been positively associated with an increase in concern for crime, perception of crime risk, and motivation to be involved in anti-crime efforts (Lavrakas et al., 1983).

Building on these approaches, Clarke (1995) proposed situational crime prevention as an approach to reduce crime by increasing the effort needed to successfully commit crime, increasing risks of doing so, decreasing the rewards associated with offending, reducing provocations, and removing excuses of offending. In other words, crime, especially conventional offenses (e.g., robbery, assault, theft), can be effectively 
prevented by potential victims or place managers as they have significant influence over these aspects. For example, to prevent theft of/from a motor vehicle, the owner could remove all of their valuables after parking, use a club to lock the steering wheel, and choose to park in well-lit, highly visible areas. Doing so removes opportunities in which offenders are most likely to commit crime, as well as prevents motivation to offend.

Drawing from broader fields, prevention through changes in behavior due to advisories is not uncommon. Mostly seen in meteorology, the public utilizes information from experts to stay informed about weather hazards and exercise preventative measures when necessary (Cairo \& Schlossberg, 2019). For example, weather advisories cautioning a coastal town of an oncoming tsunami prompt the citizens to begin storing essentials, preparing for widespread flooding, and emergency evacuations in some cases (Sheridan et al., 2011). Similarly, how the public interprets crime information may reveal similar trends in mass behavior. Therefore, risk communication by police should be guided by findings from broader fields.

More on, early concepts, like RAT (Cohen \& Felson, 1979) and pattern theory (Brantingham \& Brantingham, 1984), also highlight how an offender's likelihood of success is dependent on the convergence in space and time of motivated offenders, suitable targets, and the absence of capable guardians against crime (Cohen \& Felson, 1979). Because crime has been frequently associated with geographic influence, crime maps are considered useful tools in conveying transparency (e.g. where crime occurred) and communicating risk (where crime could occur in the future). This supports geographically based policing efforts including visualization of crime data, identification of hotspots, allocation of law enforcement resources and personnel to such locations, and 
prediction of future incident locations - all of which can eventually contribute to crime reduction and prevention efforts (Eck et al., 2005; Zhou et al., 2012).

Agency characteristics can be used to explain why some PDs deliver crime maps while others do not. The current study investigates agency size and technological capacity. Past research has found that larger agencies (Rosenbaum et al.,2011) reported higher technological capacity such as website engagement, social media use, and records management system (RMS) sophistication (Yavuz \& Welch, 2014). Using data from the 2013 LEMAS survey, Reaves (2015) reported a majority of agencies serving larger populations had their own websites, used social media, and used electronic means to transmit incident information from the field to the agency's central information system. With higher technology capacity, agencies have increased access to data, geographic information system (GIS) platforms, and the Internet. Therefore, they should naturally be more equipped to generate crime maps and deliver them to the public.

Programs, such as the PDI, push for an increase in use of data and technology by law enforcement as a mean of increasing openness. Possibly in hope that the benefits of crime maps can apply to populations outside of the agencies, more US PDs are making crime maps available to the public. Doing so would potentially allow the public access to similar technologies used by law enforcement to analyze crime activity (LexisNexis, n.d.), so they can make better-informed decisions. Earlier studies conducted by the Bureau of Justice Statistics reported increases over time in number of local PDs providing routine access to crime statistics - from 35\% in 1997 to $73 \%$ in 1999 (Wartell \& McEwen, 2001; Hickman \& Reaves, 2001). However, citizen access to crime maps was rare at that time, with only $3 \%$ of PDs providing crime maps and conducting citizen 
training on how to use and analyze mapped content (Hickman \& Reaves, 2001). Since then, due to improvements in GIS technology, access to mapping software, and easier access to the Internet, it would not be surprising if police departments have increased use of the Internet to communicate crime information to the public (Wartell \& McEwen, 2001).

Some reputed benefits of publicly accessible crime maps include: 1) reduced police workload (e.g. having to answer citizen calls inquiring general neighborhood safety and crime), 2) public access to timely information that is constantly being updated, 3) identification of hotspots and problem areas, which serves in community policing and problem solving efforts, 4) partnerships between agencies and researchers, 5) enhanced accountability of police as maps depict police activity, and 6) an increased awareness of neighborhood safety by the public (Wartell \& McEwen, 2001). In addition, third-party crime mapping companies, Lexis/Nexis and Crimemapping.com, also claim that crime mapping informs citizens about recent criminal activities, promote "more self-reliance among community members", and improves "communication between the public and law enforcement" (n.d.).

However, it is important to note that the drivers behind open data sharing are mainly policy-based (Chainey \& Tompson, 2012). As well-intended as they may be, the practice of delivering open crime maps, like all public policies, should be based on empirical evidence, which currently is "distinctly absent." (Chainey \& Tompson, 2012, p. 6) Maps, when improperly generated and interpreted, can alter perceptions and possibly become dangerous - "dangerous" because unlike most communication tools, maps (not restricted to crime maps) are, more often than not, easily trusted and viewed with little 
cynicism (Crampton, 2001). Drawing from literature of other primarily cartographic fields, experts have raised concerns about delivering maps to the general public. These concerns include lax cartographic discipline, improper communication and interpretation of cartographic illustrations and data, and a lack of understanding about how people perceive maps in general (Chainey \& Tompson, 2012; Tompson et al., 2015).

Several examples from cartography indicate maps have the potential to influence people's perceptions of places and their populations. For example, the Mercator projection "makes Europe and North America seem more important" by centering the "developed" countries on most maps, making people perceive them as more influential (Regoli, 2019). Moreover, Europe especially has been described as "egocentric" for placing themselves at the top (north) of maps when it was a dominant power in the world (University of California, Santa Barbara [UCSB], 2018, para. 2). Also, modern-day metaphors such as "feeling high" that are used to imply positive emotions and "feeling down" for negative emotions also contributes to people's perceptions of the northern hemisphere as being more important and favorable over the south - this is known as the north-south bias (UCSB, 2018, para. 1). Similar interpretations when viewing crime maps could lead to negative biases towards neighborhoods with visually dense crime counts and their residents. This could, in turn, have adverse implications, such as reduced property values and higher insurance rates in these neighborhoods, that hinder economic development perpetuating disadvantage (Wartell \& McEwen, 2001).

To ensure the least errors in perceptions, it is also important that cartographic data and illustrations are being properly communicated by agencies and correctly interpreted by the public. Examples from meteorology have shown inadequate understanding of 
weather hazard maps can influence people's behaviors and potentially put them in harm's way. Sheridan et al. (2011) highlighted that the general public often misinterprets information communicated through weather advisories, watches, and warnings. Misinterpretation sometimes leads to insufficient preparation for anticipated disasters, which in turn results in lives and properties lost that could have been saved. A recent New York Times article also described how a majority of people misinterpret hurricane maps and this in turn affect their sense of risk perception and alter safety-seeking behaviors (Cairo \& Schlossberg, 2019). For this reason, PDs should include instructions on how mapped content should be interpreted or what certain map elements indicate (e.g. showing jurisdiction boundaries and stating only crime within relevant jurisdictions are displayed, so that people do not mistakenly assume the area showing criminal incidents is relatively unsafe). Otherwise, confusion could result, and mistaken beliefs may negatively influence perceptions of neighborhood safety and crime trends.

Despite PDs delivering open crime maps, there is limited research examining public perception of such maps, which makes delivering them to the public even more concerning. Past literature has indicated that although people who viewed crime maps showed less fear of crime generally compared to those who simply viewed tabular statistics (Groff et al., 2005), certain types of maps have been reported to exacerbate different levels of fear (Groff et al., 2005; Wuschke et al., 2017; Wuschke et al., 2021) . Groff et al. (2005) reported lower fear ratings for assault and robbery in subjects who viewed graduated symbol maps compared to those who viewed density maps. Wuschke et al. (2017) also found that map types matter in that dot density maps, compared to kernel density maps, were associated with lower levels of perceived safety and higher 
perceived risk of victimization among individuals. Regardless of inconsistent findings as to which map types influences perceptions in what way, research have consistently found that differences exist. Especially when a large proportion of PDs are making crime maps available, there is a need for more research examining level of perceived safety and fear in relation with map type.

When evaluating crime maps, it is also important to understand their delivery sources and, in relation, the background processes of map generation, maintenance, and delivery. While some US PDs may choose to generate and deliver crime maps internally, others prefer utilizing third-party mapping companies for reasons such as convenience, cost, and human resource shortages (Stiglitz \& Wallsten, 1999). However, more concerns arise in doing so. Map creation and presentation decisions greatly alter the messages the final product conveys, communicating not only mere crime events but also other information that could shape perceptions of neighborhoods, safety, local policing, real estate values, and future residences. By entrusting generation and delivery of digital, interactive crime maps to private external hosts, agencies surrender a considerable amount of cartographic control (Wuschke et al., 2021). When mapping processes and presentations (e.g. type, color choice, symbol size, feature positioning etc.) are not regulated, PDs may not be able to effectively fulfill their goals of providing open crime maps. For example, dot maps may be most effective if an agency aims to raise public awareness and empower citizens to actively reduce likelihood of victimization. If the objective is to help viewers compare crime between areas, then density or choropleth may better serve this purpose. However, if an agency's goal is to be transparent about single 
criminal incidents but the external host only provides density maps, viewers cannot derive said information from said map type.

Similarly, while Eikelboom and colleagues (2017) also acknowledged the benefits of crime mapping and delivering crime maps to the public, they highlighted that incomplete and/or inaccurate presentation of map data could have adverse social and economic consequences. For the public to be able to make well-informed decisions regarding crime and safety, it is crucial that PDs are transparent in descriptions of data shared and omitted. For instance, North American crime maps randomly offset crime locations, and it should be disclosed that this is done for a purpose (e.g. to protect the privacy of victims). The processes by which agencies include/exclude data and geocode crime locations could alter how people perceive crime maps. In addition, mentioning the recency of data might be may also help the public make better inferences about neighborhood safety (Eikelboom et al., 2017). Therefore, it is important to investigate how PDs make such decisions and if they are reporting these processes. The use of crime maps is intended to communicate risk and build police legitimacy in the first place, so incomplete or inaccurate descriptions of map creation and maintenance processes could generate confusion among the public. This may not serve their potential objectives (e.g. risk communication, transparency, enhancing legitimacy, etc.) effectively.

To conclude, crime maps are being delivered to the public by PDs. However, very limited research has investigated if such practices are resulting in the expected benefits. Based on concerns presented by experts and past researchers, they could also result in unanticipated adverse consequences for PDs, the public, or both. The current study will therefore explore some basic statistics regarding prevalence of crime maps, map type, 
delivery source, possible reasons of map delivery, and associated metadata provided by agencies.

\section{Research Questions}

RQ1: How many PDs provide public access to interactive crime maps and is the number increasing overtime?

A Bureau of Justice Statistics (BJS) study reported that PDs have long provided routine access to crime data (through the telephone, newspaper, written reports etc.), and there have been an increase in crime data provision by PDs overtime - from 35\% in 1997 to $73 \%$ in 1999 (Wartell \& McEwen, 2001; Hickman \& Reaves, 2001). However, public crime maps were rarely used then, and only $3 \%$ of PDs reported providing crime maps (Hickman \& Reaves, 2001). Public demand for increased government transparency, building emphasis on community policing and realization of the need of citizen collaboration in crime prevention, and increased access to technology and the Internet were discussed as possible factors behind why agencies may be delivering crime maps to the public. Considering these factors, the study poses the first hypothesis.

H1: The number of PDs providing public crime maps is expected to have increased between 2013 and 2020.

RQ2: How are the maps delivered?

The field of crime mapping has seen drastic technological advances since the 1990s; the latest improvements include cloud and mobile computing. This allows for faster data collection and data transfer to other officers, agencies, and civilians. This advancement has led to the rise of for-profit online mapping companies which provide crime data to the public. These companies generate crime maps for public consumption 
using data from agencies and provide additional map services such as regular updates, data storage, customer service (Paulsen \& LeBeau, 2012). Doing so helps decrease the workload of agency staff, whose efforts could be focused on real-life crime reduction and prevention. In addition, external companies are specialized and, therefore, are expected to offer better technological prospects. As for-profit organizations with sufficient funding, they are also more likely to have better information of potential market success as well as more reliable predictions of market outcomes than government agencies (Stiglitz \& Wallsten, 1999). For these benefits, PDs may choose to deliver crime maps externally instead of generating and publishing them only using internal resources. However, it is important to note that by entrusting generation and delivery of digital, interactive crime maps to private external hosts, agencies surrender a considerable amount of cartographic control (Wuschke et al., 2021). When mapping processes and presentations (e.g. type, color choice, symbol size, feature positioning etc.) are not regulated, PDs may not be able to effectively fulfill their goals of providing open crime maps. Delivering maps through external hosts may be most beneficial for agencies that are simply willing to be transparent and demonstrate they are sharing crime data with the public.

H2: Due to higher convenience of generating and maintaining maps through third-party companies, it is expected that more PDs will deliver public crime maps through external hosts than internally.

\section{RQ3: What types of maps are available?}

It is important to recognize that PDs may deliver different types of maps depending on objectives of providing crime maps. A map type, specifically for the use of transparency, may be different from one used to communicate risk. Therefore, dot maps 
might be mainly used to indicate locations of criminal activity (i.e. for transparency), while density maps may be more useful in visualizing hotspots and predicting future crime locations (i.e. risk communication). However, due to the diverse factors involved in map creation, maintenance, and delivery described above, the researcher will not attempt to generate a specific hypothesis regarding prevalent map types.

RQ4: What agency characteristics are associated with delivery of public crime maps?

Characteristics of agencies providing maps should also be contrasted against those that do not. Past research has found agencies that were larger in size, those with a heavier community policing emphasis (Rosenbaum et al., 2011), and higher technological capacity (e.g. website engagement, social media use, and RMS sophistication) (Yavuz \& Welch, 2014) to be more likely to have websites. Because crime maps are primarily delivered through websites, characteristics associated with website availability may influence crime map availability as well. In addition, agencies in areas with higher crime rates were more likely to have and maintain websites. However, results only indicated mixed support for their hypothesis that agencies with heavier emphasis on community policing are more likely to provide crime information and opportunities for public input on their websites (Rosenbaum et al., 2011).

Technological capacity (Yavuz \& Welch, 2014) has also been related to an agency's ability to provide and maintain websites. Such abilities may be also directly applicable to crime maps. At this point, it is important to note that (as also described by Reaves (2015)) agencies serving larger populations in 2013 were also the ones reported higher technological capabilities. Therefore, they may more likely be able to share crime- 
related data from their electronic RMS as part of their community policing using channels such as agency websites and social media accounts. Guided by literature, the current study explores the associations between delivery of crime map and agency characteristics such as size, community policing focus, and technological capacity (website sophistication, social media engagement, records management system (RMS) sophistication).

H4a: Larger agencies will be more likely to provide open crime maps.

H4b: Agencies with stronger commitment to community policing will be more likely to provide open crime maps.

H4c: Agencies with higher website engagement will be more likely to provide open crime maps.

H4d: Agencies with higher social media engagement will be more likely to provide open crime maps.

H4e: Agencies with more sophisticated RMS will be more likely to provide open crime maps.

RQ5: Do PDs explain why they are providing crime maps, and if so, what are their stated reasons?

Purpose precedes actions, and actions have to be accompanied by justifications. Past research has suggested that different map types fulfill objectives differently (Groff et al., 2005; Wuschke et al., 2021). For example, an agency aiming for enhanced transparency and prioritizes displaying crime incident locations, then dot maps may be the best option. Another agency striving to help community members engage in crime prevention and assess future risk, then kernel density maps may be more suitable. 
Therefore, it is important that agencies carefully consider why they provide open crime maps and communicate these reasons to viewers (Quinton, 2011; Wuschke et al., 2021).

For example, Naperville PD, explicitly state they provide open crime maps to improve "community awareness of public safety activity." (n.d.) In this case, a dot map displaying locations of police activity should fulfill Naperville PD's objective. The Roseville PD (n.d.) claims not their crime mapping will not only increase awareness but also "assists citizens in taking an active role in protecting themselves and improving safety in their neighborhoods and businesses." In this case, it may be in the best interest of Roseville PD to provide more than one type of map so that both their stated goals are fulfilled. In addition to enhancing awareness and crime prevention, the Fargo PD (n.d.) states they have partnered with an external mapping company to also increase data transparency with the public. Some, such as Great Falls PD (n.d.), cite collaboration between police and the community as the main reason for providing crime maps. As can be seen in the examples, because objectives of providing crime maps can be diverse, it is important that agencies consider and disclose them properly, and if possible, provide map types that effectively satisfy said reasons. However, limited research has explored why US PDs provide crime maps, and therefore, the study deemed it appropriate to evaluate justifications agencies offer for such a practice. Due to a combination of lack of research and the possibility of countless unanticipated reasons PDs could have for delivering open crime maps, the researcher will not attempt to generate a specific hypothesis.

RQ6: How many PD crime maps are accompanied by metadata?

Duval (2001) defines metadata as 'data about data.' (p. 591) Metadata are a crucial component of digital features as they "facilitate search, evaluation, acquisition, 
and use of resources." (Duval, 2001, p. 591) Crime maps, being digital and maps, should therefore be accompanied by explanations of mapped content, content generation, map maintenance, and presentation. Drawing from the broader field of computer science, providing metadata with crime maps should help viewers better search for, evaluate, and comprehend the crime- and policing-related information shared by PDs.

Different decisions of map and data generation, maintenance, and delivery could result in different maps. Police are responsible for a wide range of responsibilities. Some examples of policing tasks include traffic accidents, criminal incidents, medical emergencies, and welfare checks (University of North Carolina at Chapel Hill, n.d.). Therefore, some basic metadata agencies should offer regarding map and data generation include the type of incidents mapped, how they were generated from the field (e.g. citizen reports, officer reports), and if any incidents were left unmapped. Similarly, once a map has been created, it becomes important to maintain mapped content. To provide a more complete understanding of the "working-ness" of a crime map for viewers, agencies should offer metadata on map and data maintenance processes such as data recency, update frequencies, data revisions, etc.

Finally, the author outlines two examples of why being informed of decisions made in the map presentation and delivery process is crucial. On a dot map, an agency chooses to map only one category of crime in an area now but decides to map two categories of crime two weeks later. Such failure to disclose changes in decision could lead viewers to assume crime has risen significantly in said area over two weeks, resulting in lower levels of perceived safety and higher perceived risk of victimization. As a second example, kernel density maps are notorious for their "high variable output 
resulting from changes to input" (Chainey et al., 2002). This means slight changes in creative factors such as preferred bandwidth (more commonly known as the search radius) and cell size (i.e. resolution) can result in two maps displaying identical data to appear almost unrecognizable from each other.

Providing metadata along with crime maps will further fulfill risk communication and transparency objectives. For instance, in considering future residence locations, describing recency of data will help new residents more accurately evaluate crime within an area. Areas that were considered hot spots in the past year may not be as concentrated in crime now, which will lower their fear of property crimes (e.g. theft from automobiles, burglary) and increase perceptions of safety. Similarly, informing viewers whether or not all data has been made available, or if events have been excluded and why would benefit transparency goals as well. Providing metadata should therefore not only heighten viewers' confidence of the displayed crime data, but also of their local police and their crime control efforts. When the public recognize the transparency with which agencies communicate, this could in turn contribute to higher trust in local police and even empower community members to collaborate with authorities.

However, because there has been no research investigating the amount and type of metadata offered by US PDs before, the researcher will not attempt to generate a specific hypothesis.

\section{Methodology}

\section{Sample}


Data for the current study came from the 2013 Law Enforcement Management and Administrative Statistics (LEMAS) survey. This survey is conducted every three to four years by the BJS. The 2013 survey included all U.S. law enforcement agencies listed in the Census of State and Local Law Enforcement Agencies (Reaves \& Hickman, 2008), consisting of more than 12,000 PDs, sheriff departments, and state police agencies. The CSLLEA groups all agencies into seven population strata based on the number of sworn officers employed, including one full-time equivalent (FTE) officer, two to four officers, five to nine officers, 10 to 24 officers, 25 to 49 officers, 50 to 99 officers, and 100 or more officers.

In preparation for the 2013 LEMAS survey, the BJS created a sampling framework by selecting all agencies with more than 100 officers and supplementing this with random samples taken from each stratum with fewer than 100 officers. This process generated a combined list of 3,336 law enforcement agencies. A small number of agencies were subsequently eliminated, including 26 agencies that had closed since the 2008 CSLLEA, and another nine were dropped for unknown reasons. This reduced the sample to 3,301 law enforcement agencies. The BJS mailed each agency a survey packet with instructions. A small number $(n=29)$ did not receive the survey due to inaccurate contact information, leaving 3,272 agencies. The BJS received a survey from 2,822 of these agencies, yielding a response rate of $85.5 \%$.

The sample of agencies participating in the 2013 LEMAS study was further reduced within the current study. Given the focus on municipal police departments, all sheriff's departments $(n=717)$, state police agencies $(n=46)$ and tribal-operated police agencies $(n=23)$ were removed from the study. One additional agency missing a unique 
identifier supplied by the Federal Bureau of Investigations (FBI) was eliminated as well, resulting in a sample of 2,035 non-tribal PDs. Only municipal police departments were analyzed in this study for three reasons. Firstly, municipal police departments comprise the majority of law enforcement agencies in the 2013 LEMAS survey. Secondly, unlike sheriff's departments and state police, the jurisdictions of municipal police departments are more specific. Thirdly, unlike tribal police, the jurisdiction and powers of municipal police in law enforcement are not limited to tribal lands or populations (BJS, 2021). Specificity in identification of municipalities served (i.e. cities, towns, villages, etc.) and the authority of local police over general populations enable more accurate comparisons of populations served and agency size.

A final adjustment to the sample was made to expedite the coding process to account for time constraints and the low probability of smaller PDs having either websites, crime maps, or both. Rather than retain all of the agencies with 1 to 9 officers $(n=467)$ and 10 to 24 officers $(n=391)$, we randomly selected 250 from each stratum. ${ }^{1}$ When combined with BJS' other strata - 25 to 49 officers $(n=321), 50$ to 99 officers (n $=284)$, and 100 or more officers $(n=572)-$ this generated a final sample size of 1,677 police agencies.

\section{Procedures}

Three sources of data were coded for each police department sampled. First, we used the responses to the 2013 LEMAS survey to create several variables. Secondly, we conducted an online search in 2020 for each police department to determine if they had a

\footnotetext{
${ }^{1}$ This decision was supported by preliminary analyses showing that smaller agencies were less likely to have a website and online crime maps.
} 
website with a unique uniform resource locator (URL). If they did, we investigated further to determine if the PD provides open crime maps. Finally, in 2021, we returned to PDs that had crime maps in 2020 to document whether or not they offer justification(s) for providing open crime maps and, if they do, the type of justification - i.e. none, nonspecific, or specific. Finally, along with PD justification, a metadata review was conducted to evaluate whether or not PDs offered explanations along with their crime maps.

\section{Measures}

\section{LEMAS Survey}

Firstly, six variables were extracted from the 2013 LEMAS survey.

Website \& Crime Map 2013. The 2013 LEMAS survey asked the following question: “As of January 1, 2013, what crime-related information did your agency provide to the public on its WEBSITE?” (p. 317) The first response option provided was: "Agency has no website". If the agency had a website, they were asked whether it was used to provide public access to, "Street-level maps that report the location and nature of a variety of specific crimes." The responses to these questions were used to create two dichotomous variables $(0=$ no; $1=$ yes $)$ reflecting whether the agency had a website in 2013 and whether they provided online crime map(s) in 2013.

Agency Size. Agency size have been shown to be related to crime map availability on websites, in that larger agencies are more likely to provide crime maps (Reaves, 2015). Agency size was determined based on responses to the following question: "As of January 1, 2013, how many paid sworn personnel worked in your agency?" Agencies responded by identifying the number of male and female full-time officers. The current 
study combined these responses into five population strata - one to nine officers, 10 to 24 officers, 25 to 49 officers, 50 to 99 officers, and 100 or more officers (the 2013 LEMAS survey referred to the as self-representing (SR) agencies).

Community Policing Focus. Several prior studies used the LEMAS data to assess agencies' commitment to community policing (Goldstein, 1987; Thurman \& Reisig, 1996; Carter \& Fox, 2019). A similar strategy was used in the current study. An 8-item scale was created using the questions from the 2013 LEMAS survey. Each item was dichotomously coded, resulting in a scale that ranged from 0 to 8 . The first three items were: the nature of the agency's written mission statement $(0=$ no statement or statement contains no community policing component, $1=$ statement contains community policing component), and the proportion of full-time sworn personnel who underwent a minimum of eight hours of training on community policing standards during recruitment $(0=$ none, $1=$ some or all $)$ and in service $(0=$ none, $1=$ some or all $)$. The remaining five evaluated if an agency: a) encourages officer engagement in SARA (scanning, analysis, response, and assessment) policing, b) includes collaborative problem-solving tasks in evaluating patrol officers, c) if they have established community partnerships or agreements, d) regularly designate the same patrol officers to fixed geographic areas, and e) conduct and utilize community surveys to guide their community engagement. Responses to the eight items were summed to construct a final community policing focus scale, with a reliability coefficient (Cronbach's $\alpha$ ) of 0.66 . As the coefficient was above 0.60 , the reliability of the scale was considered to be suitable (Cortina, 1993).

Website Engagement. Police websites may be used to improve communication with the public, promote public engagement with public safety, and increase the 
likelihood of collaborative crime control efforts in the communities (Jones \& De Guzman, 2011). Therefore, agencies that are accustomed to communicating with the public via their websites may also be more likely to communicate crime data (including crime maps) using their websites. Naturally, agencies with higher website engagement may also be more likely to offer public access to online crime maps. Based on this notion, eight website engagement variables in the 2013 LEMAS survey were extracted to represent the degree of information exchange between police and citizens. The first four items assessed whether or not agencies provided the following on their websites: summaries of crime statistics by jurisdiction, summaries of crime statistics by determined geographic areas, street-level crime maps for specific crimes, and street-level sex offender residence maps. Responses were coded dichotomously for each type of information the agency provided $(0=$ no; $1=$ yes $)$. The remaining items assessed whether or not the public engaged with agencies in the following way: crime reporting, inquiries and feedback, and filing complaints. Responses were coded dichotomously $(0=$ no; $1=$ yes) for each method the public engaged with agencies through their websites. Responses to these eight items were summed to construct a final website engagement scale $(\alpha=$ 0.76).

Social Media Use. Another way that PDs might engage with the public is via social media. When used effectively, social media can increase police interaction with the public, distribute crime-related information, as well as collect intelligence relevant to criminal investigations (Dai et al., 2017). Police presence on social media helps them appear more accessible to community members, and the ease and speed with which one can contact the other is likely to encourage communication between the two parties (i.e. 
benefit community policing and increase collaboration). Information provided by select community members can then be distributed to a larger audience through other channels such as agency websites and crime maps. Therefore, agencies that are available on social media are more likely to deliver crime maps. Variables selected from the 2013 LEMAS survey to measure social media use were: a) if public reporting to agencies through electronic means (e.g. email, text) is enabled $(0=$ no; $1=y e s), b)$ if the public can choose to be notified of crime and other issues via through electronic means $(0=$ no; $1=$ yes $)$, and c) and whether or not agencies are available on the following social media platforms: Twitter, Facebook, Google+, blogs, Youtube or other video-sharing services, mass communication/notification system (e.g. Nixle), and others. Agency responses were also dichotomously coded $(0=$ unavailable; $1=$ available $)$ for each platform. Responses to the seven variables were summed to create a social media use scale $(\alpha=0.63)$.

Records Management System (RMS) Sophistication. Electronic RMS greatly increases the efficiency with which records can be transmitted, processed, stored, and retrieved (Nizich, 2012). Therefore, the delivery of online crime maps is likely to be influenced by an agency's access to electronic records. As such, a scale was created to assess each agency's RMS sophistication. The 2013 LEMAS survey asked the following question: "As of January 1, 2013, what was the primary method for transmitting criminal incident reports from the field to your agency's central information system?" Response options offered were a) paper report, b) voice transmission (e.g. radio, phone), c) smartphone, or d) computer. Responses were recoded dichotomously as non-electronic (0) for agencies primarily transmitting through paper reports and voice transmissions. The rest, transmitting through smartphone and computer, were recoded as having 
electronic (1) transmission systems. Secondly, agencies indicated if each of the following types of data are included (1) or not included (0) in their computerized records of criminal incidents: offense description, offense codes (e.g. NCIC, UCR), state statues or municipal offense codes, victim characteristics, suspect characteristics, offense location (e.g. street address, cross streets), geocoded address (X,Y coordinates), and offense date and time. Coded responses to the nine items were summed to measure each agency's RMS sophistication $(\alpha=0.74)$.

\section{Website Availability and Crime Maps (2020)}

The 2020 data collection involved online searches for agency websites and crime maps, identifying their delivery sources (i.e. internally or through external hosts), determining the types of map made available for the public by police, and if they were working.

Website and Crime Map 2020. Consistent with Rosenbaum et al. (2011), a website was defined as "at least one valid webpage accessible by the public via the Internet." (p. 31) Website search in 2020 was conducted in one of two of the following ways. Firstly, the URLs of PD websites obtained from a prior study were used to confirm if PDs still had a functioning website. If a PD was found to still have a functioning website that is publicly accessible, then they are marked as "having a website" (i.e. $1=$ yes). If a URL was not recorded for a certain PD in 2018, a Google search using PD name and state was conducted for verification. If the search did not return results of a website, then the PD was marked as "not having a website" (i.e. $0=$ no). In cases where a PD website was no longer accessible through the recorded URL but still provides a website through a modified one, web links in the prior dataset was updated to match 
current URL information. PD webpages may be a separate landing page by themselves or, at times, be embedded within a broader government website.

For an agency website to be identified as having a crime map(s) in 2020, the webpage needed to allow public access to at least one interactive online map displaying crime and policing-related data within the agency's jurisdiction. Eligible crime maps fulfilled at least one aspect of the following criteria: 1 . must be readily accessible via an actual webpage rather than contained in an downloadable document, 2 . must be accessible via agency's landing page, subpage, or links on either, and 3 . the agency must definitively state (e.g. "click here to view crime in your area) or label (e.g. "crime map", “crime reports") that these maps depict crime or policing-related information within a geographic area. In some cases, maps may not exclusively display crime- or policingrelated data and may also represent other city-wide level data such as zoning, parking, water distribution channels, etc. Agencies providing crime maps were coded as 1 (yes), those that did not were coded as 0 (no). To ensure accuracy, a second rater randomly selected 100 agencies and documented whether or not they had websites and provided crime maps. Interrater reliability analysis revealed Cohen's kappa values of 0.90 and 0.84 for evaluations of website and crime map availability respectively, indicating almost perfect agreement (McHugh, 2012).

Delivery Source. This measure identified the agency or organization providing the crime maps. Some agencies may choose to deliver internally generated maps, while others, for reasons such as convenience, limited workforce, and cost-effectiveness, may deliver maps through third-party mapping companies (Stiglitz \& Wallsten, 1999). To be recognized as a third-party mapping company, the organization must provide access to 
crime- and policing-related data from other agencies in addition to the current PD. Whether an agency provided internally generated maps $(0=$ no, $1=$ yes $)$ and externally generated maps $(0=$ no, $1=$ yes $)$ was evaluated. For PDs which offered maps through external hosts, the name of the company was recorded. Interrater reliability analysis revealed a Cohen's kappa of 0.81, again indicating substantial agreement (McHugh, 2012).

Map Type. Prior research has shown that in addition to influencing perceptions of safety and neighborhood characteristics (Wuschke et al., 2021), different map types vary in suitability for certain objectives (Harries, 1995). For example, dot maps may effectively depict locations of criminal incidents but are not as reliable in representing crime patterns as density maps. Therefore, the types of map available for each agency were documented. The types of maps delivered by each agency were coded, including dot map $(0=$ no; $1=$ yes $)$, density map $(0$ or 1$)$, choropleth map $(0$ or 1$)$, and other $(0$ or 1$)$.

Working Map. At times, agency websites may have maps that may not display recent crime- or police-related data due to failure to update information. Therefore, whether or not crime maps were working on each agency website was explored. For a map to be identified as "working," it had to display at least one policing-related incident (e.g. crime, calls for service (CFS)) within the past six months from the date of data collection. Crime maps were coded either working (1) or non-working (0). Interrater reliability analysis revealed a Cohen's kappa of 0.78 , indicating substantial agreement (McHugh, 2012).

\section{Map Justification}


Crime Map 2021. Firstly, due to a delay between the two phases of data collection as well as obstacles produced by COVID-19, it was necessary to confirm if agency that had crime maps in 2020 still provided them in 2021. This variable was dichotomously coded $(0=$ unavailable, $1=$ available $)$.

As discussed previously, one of the study objectives was to document the reasons PDs provide for making online crime maps available. The 2020 website search suggested that agencies were distributed into three categories: 1) agencies that gave no justification or explanation for their maps, 2) agencies that gave a non-specific justification, and 3) agencies that listed a specific purpose or objective for sharing crime maps with the public. Therefore, PD justification was evaluated by reviewing website content, specifically texts accompanying the crime maps (if any). A preliminary informal review led the researcher to believe that agencies could be classified into three groups: (0) no justification, (1) non-specific justification, and (2) specific justification. This review was conducted strictly on information provided by agencies. Information on third-party websites did not apply (see Appendix A for the complete list of items).

Justification for maps. Agencies were coded as offering "no justification" if they had no informative text to accompany the link to their maps. Figures 1 and 2 illustrate some examples of agencies offering no justification.

Agencies were coded as offering "non-specific justification" if they identified generic goals of providing crime maps. Non-specific justifications contain no detailed explanations of how police-related information can be effectively utilized and/or intended achievements for themselves or the public by providing crime maps. Examples of nonspecific justifications are provided below: 


\section{Figure 1}

Rochester PD Crime Map Link

\section{Click the below image to view Rochester's crime map.}

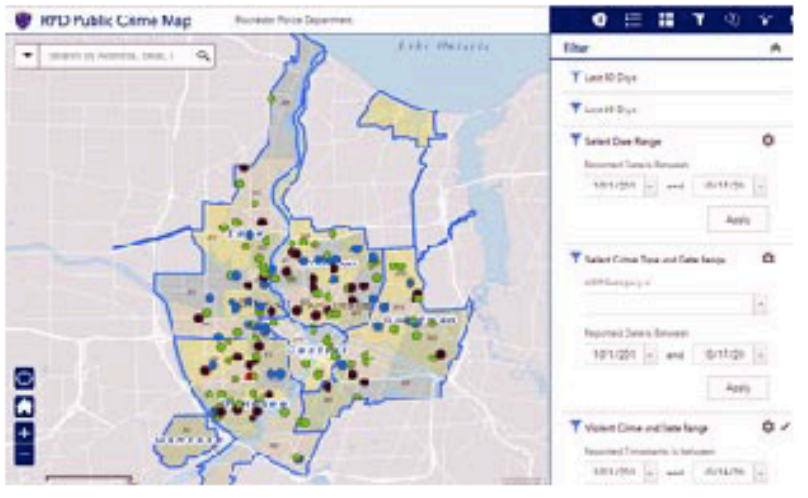

\section{Figure 2}

Saint Petersburg PD Crime Map Link

\section{Stat Map - Citizen calls for service}

Click to open Stat Map and see police calls on an interactive map.

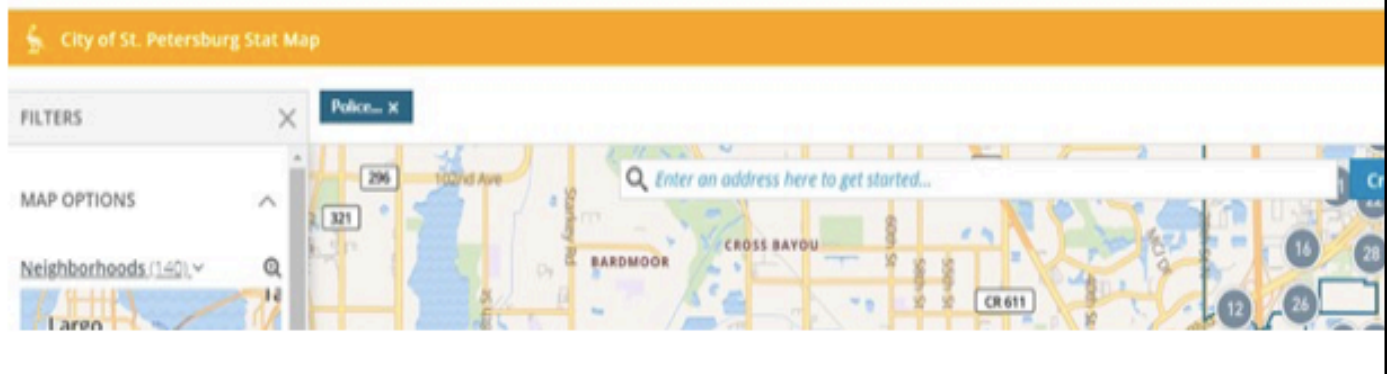

"The new Crime Incident Mapping Application is an application that has been developed to provide recent crime activity within the City of Long Beach. It provides the Public with easy-to-use tools to search and query crimes within their communities." (Long Beach Police Department, n.d.) 
"The Raleigh Police Department has an online crime-mapping tool that makes it convenient for people to learn of crimes reported in areas that are of interest to them." (Raleigh Police Department, n.d.)

"The Police Department provides residents and business owners the ability to look into crime that occurs in their community and neighborhoods through CityProtect.com, formerly known as CrimeReports.com." (Prince William County Police Department, n.d.)

"We've partnered with LexisNexis to bring you community crime data." (Kansas City Police Department, n.d.)

"The Mesquite Police Department has launched their new online crime mapping website which provides the public with information about crimes reported within the City of Mesquite.” (Mesquite Police Department, n.d.)

Finally, agencies were coded as offering "specific justifications" if they clearly identified one or more reasons for providing access to the public. Through an informal review, the researcher was able to identify a few types of specific justification offered. Themes were noted down, and agencies were dichotomously coded for mentioning (1) or not mentioning (0) the following reasons within texts accompanying their crime maps: a) risk communication to improve awareness, b) risk communication for crime prevention, c) improving legitimacy through transparency, d) improving legitimacy through trustbuilding, and e) collaboration between police and community members.

\section{Metadata Review}

As described earlier, crime maps should be accompanied by additional information to aid understanding of the mapped content and depictions of crime- and/or policing-related data. This additional information is often referred to as 'metadata', which Duval (2001) defined as 'data about data.' (p. 591) Our preliminary informal review suggested that the types and quantity of metadata offered by PDs may vary. Therefore, whether or not PDs offered metadata on the following four aspects of crime maps was 
evaluated: a) data generation, b) geocoding and offsets, c) data and map maintenance, and d) map type documentation (see Appendix B for the complete list of items). Metadata review was conducted for agency websites with crime maps in 2021 and strictly on information provided by agencies; information on third-party websites were not reviewed.

Data Generation. Police officers handle a selection of incidents that are diverse in nature. Some examples of policing tasks include traffic accidents, criminal incidents, medical emergencies, and welfare checks (University of North Carolina at Chapel Hill, n.d.). As indicated in the 2013 LEMAS survey, reports of such incidents can be generated by either police officers or member of the public through several electronic and nonelectronic means. Therefore, firstly, whether or not agencies identified one or more of the following metadata related to mapped data was evaluated: a) the type(s) of data being mapped (e.g. criminal incidents, CFS), b) data sources (e.g. officer-initiated reporting, citizen reporting through phone, online reporting), c) limitations associated with identified data sources (e.g. one CFS may involve multiple incidents, not every 911 call concerns a criminal incidents etc.), d) excluded incidents originally present in data sources (e.g. ongoing investigations, sexual offenses), and e) reasons for withholding such incidents from crime maps. Agencies were coded dichotomously for each type of mapped data information they identified $(0=$ no; $1=$ yes $)$.

Geocoding and Offsets. Geocoding involves transforming descriptions of locations (e.g. coordinates, addresses, location name) into comprehensive location information, which can then be used in mapping to reflect coordinates, addresses, or map features (Environmental Systems Research Institute [ESRI], 2020). In addition to 
geocoding, offsetting involves displacing or moving features for reasons ranging from improved readability to protecting victim's privacy (ESRI, 2020). These two processes, separately or combined, could result in changes on the final crime maps depending on how agencies geocode and/or offset incident locations. This can influence perceptions of crime and safety in neighborhoods. Therefore, we evaluated whether or not agencies identified within their metadata: a) if the mapped data underwent geocoding, b) the type of data geocoded (e.g. incident starting location, incident ending location), c) how incident addresses are recorded, d) geocoding accuracy (e.g. rooftop of building at address, nearest intersection, block midpoint), e) if mapped incident locations are modifications of reported locations, f) the extent of offsets (exact, block midpoint, intersection), g) if all or only select incidents undergo offsetting, and h) reasons behind their decisions for such modifications. Agencies were coded dichotomously for each type of geocoding and offset information they provided $(0=$ no; $1=$ yes $)$.

Data and Map Maintenance. To avoid confusion and ensure clarity among viewers, agencies should provide supplemental descriptions concerning data categories and map maintenance processes along with their crime maps. Therefore, we reviewed whether or not agencies provided one or more of the following types of supplemental information on webpages preceding or containing crime maps/links to crime maps: a) explicit descriptions of data subcategories, differentiating each type of incident, b) crosswalk documents showing how local PD incident categories compare to those defined by mapping companies, in cases of externally generated maps, c) metadata on map maintenance processes such as data transfers, updates, and recency, d) update frequencies on metadata and/or crime map, e) clarifications on delays, informing viewers 
of dates or times of the latest incidents displayed, f) discussions of data revisions to account for revised incidents such as reopened investigations and case updates. Agencies were coded dichotomously for each type of map maintenance information they provided $(0=$ no; $1=$ yes $)$

Map Documentation. Map types have been shown to vary in the extent they influence public perceptions of safety (Wuschke et al., 2021) and fulfill certain objectives (Harries, 1995). Therefore, it is only reasonable that agencies provide metadata on the crime maps themselves. Therefore, whether or not agencies documented in their metadata one or more of the following was evaluated: a) available map type(s), b) map creation decisions such as projection, scaling, other spatial references that could alter final map displays, c) caveats associated with each map type available, and d) displaying raw, unmodified incident counts. Again, agencies were coded dichotomously for each type of map documentation information they provided $(0=$ no; $1=$ yes $)$.

\section{Analytic Plan}

The current study examines crime map availability in a sample of 1,677 US PDs, how the maps are delivered, what types of map are commonly provided, agency characteristics associated with crime map delivery, and whether or not agencies offer justifications for and metadata along with their maps. Firstly, frequency analysis and a chi-square test of independence was conducted to determine crime map availability in 2013 and 2020 and change overtime. Secondly, frequency analyses were mainly used to investigate map delivery source and map types delivered. Thirdly, to examine the associations between agency characteristics and crime map delivery, chi-square tests of independence and a binary logistic regression were conducted. Lastly, frequency analyses 
were utilized to determine how many agencies provided justifications and metadata along with crime maps.

\section{Results}

RQ1: How prevalent were online, interactive crime maps among the sample of US PDs explored and has the number increased overtime?

Frequency analyses revealed that the number of available PD websites, along with open crime maps, increased. In 2013, 84.4\% ( $\mathrm{n}=1403)$ of PDs had working websites, and $30.6 \%(n=508)$ of them provided open crime maps. In 2020, the availability of PD websites and open crime maps increased to $93.7 \%(n=1574)$ and $34.9 \%(n=586)$ respectively. A $2 \times 2$ chi-square test of independence indicated no significant difference in crime map availability between 2013 and $2020\left(\chi^{2}(1, \mathrm{~N}=1677)=0.33, p=.56\right)$. It is important to note that the current study only accounted for interactive crime maps on PD websites. The 2013 LEMAS survey question concerning crime maps did not require agencies to specify whether or not their maps were interactive. This could have resulted in an inflated estimate of online crime map availability in 2013. Therefore, it is possible that the increase in web, interactive crime maps between 2013 and 2020 may be higher in reality than currently reported.

RQ2: How are the maps delivered?

More maps were found to be delivered through external hosts than internally. Of the 586 agencies that provide crime maps, $19.1 \%(\mathrm{n}=112)$ generate their maps internally, while $82.1 \%(\mathrm{n}=481)$ deliver crime maps through external hosts. A small number $(1.2 \% ; \mathrm{n}=7)$ delivered both internal and external crime maps; therefore, addition 
of delivery source statistics do not reflect a perfect $100 \%$. The proportion of working internal and external maps were $97.3 \%(n=110)$ and $92.3 \%(n=444)$ respectively. Further analyses revealed that maps were externally generated and delivered by the following companies, listed by prevalence: RaidsOnline/LexisNexis $(41.0 \% ; n=198)$, CityProtect $(31.0 \% ; \mathrm{n}=149)$, and Crimemapping.com $(24.0 \% ; \mathrm{n}=117)$. These three companies combined accounted for $96 \%$ of crime maps provided by police to the public, making them the most dominating third-party mapping services used by the sampled PDs. The remaining $4 \%$ of agencies $(n=17)$ delivered crime maps through other external hosts such as Crime Watch Maps, and MapNimbus.

RQ3: In 2020, what types of maps are available?

Of the agencies that delivered maps internally, $92.0 \%(\mathrm{n}=104)$ had dot maps, $14.2 \%(n=16)$ density maps, $7.1 \%(n=8)$ choropleth maps, and $0.2 \%(n=1)$ other types. Of agencies delivering externally generated maps, $99.8 \%(n=480)$ had dot maps, $41.0 \%(n=197)$ density maps, $0.4 \%(n=2)$ choropleth maps, and $2.7 \%(n=3)$ other types. It is important to note that one of the external companies, RaidsOnline/LexisNexis, offers both dot maps and density maps.

RQ4: What agency characteristics were associated with delivery of public crime maps?

Firstly, chi square $\left(\chi^{2}\right)$ tests of independence were conducted to examine the relationships between each agency characteristic and crime map availability in 2020 (see Table 1). There were significant associations between map availability in 2020 and agency size, $\chi^{2}(4, \mathrm{~N}=586)=412.45, p<.001$; community policing focus, $\chi^{2}(3, \mathrm{~N}=$ $586)=178.91, p<.001$; website engagement, $\chi^{2}(3, \mathrm{~N}=586)=253.50, p<.001$; social 
media use, $\chi^{2}(3, \mathrm{~N}=586)=177.48, p<.001$; and RMS sophistication, $\chi^{2}(3, \mathrm{~N}=586)=$ $22.79, p<.001$.

\section{Table 1}

Bivariate Analyses of Characteristic and 2020 Map Availability

\begin{tabular}{|c|c|c|c|c|}
\hline & $\begin{array}{c}\% \text { of } \\
\text { agencies }\end{array}$ & $\begin{array}{l}\% \text { of online } \\
\text { crime maps }\end{array}$ & $\chi^{2}$ & Sig. \\
\hline Agency size (no. of sworn officers) & & & 412.45 & $.000 * * *$ \\
\hline$<10$ & 13.7 & 0.2 & & \\
\hline 10 to 24 & 16.3 & 6.0 & & \\
\hline 25 to 49 & 20.2 & 12.3 & & \\
\hline 50 to 99 & 17.4 & 22.0 & & \\
\hline 100 or more & 32.4 & 59.0 & & \\
\hline Community policing focus & & & 178.91 & $.000 * * *$ \\
\hline 0 to 1 & 14.0 & 4.6 & & \\
\hline 2 to 3 & 26.9 & 16.0 & & \\
\hline 4 to 5 & 30.0 & 34.3 & & \\
\hline 6 or more & 29.2 & 45.1 & & \\
\hline Website engagement & & & 253.50 & $.000 * * *$ \\
\hline 0 to 1 & 32.4 & 11.3 & & \\
\hline 2 to 3 & 26.5 & 24.4 & & \\
\hline 4 to 5 & 24.0 & 34.4 & & \\
\hline 6 or more & 12.1 & 29.8 & & \\
\hline Social media engagement & & & 177.48 & $.000 * * *$ \\
\hline 0 to 1 & 24.3 & 9.6 & & \\
\hline 2 to 3 & 38.2 & 33.4 & & \\
\hline 4 to 5 & 29.3 & 44.2 & & \\
\hline 6 to 7 & 8.2 & 12.3 & & \\
\hline RMS sophistication & & & 22.79 & $.000 * * *$ \\
\hline 0 to 1 & 2.1 & 0.5 & & \\
\hline 2 to 3 & 0.9 & 0.5 & & \\
\hline 4 to 5 & 5.8 & 3.4 & & \\
\hline 6 or more & 91.2 & 95.6 & & \\
\hline
\end{tabular}

A binary logistic regression was conducted to estimate the extent to which five agency characteristics were associated with the likelihood of map provision. Results 
indicated that agency size $(\beta=0.001, p<.001)$ significantly predicted the likelihood of map provision (see Table 2 ). Characteristics such as higher community policing focus ( $\beta$ $=0.226, p<.001)$, higher website engagement $(\beta=0.247, p<.001)$, and higher social media use $(\beta=0.165, p<.001)$ were found to predict the likelihood of agencies providing crime maps. All variables were found to be statistically significant $(p<.001)$ with the exception of RMS sophistication $(\beta=0.107, p=.056)$. However, it is important to note that statistical significance does not necessarily translate to meaningful effect sizes. Altogether, the tested variables explained $30.7 \%$ of variance $\left(\mathrm{R}^{2}=0.307\right)$. Table 2 outlines the regression analysis findings on agency characteristics and their likelihood to provide crime maps in 2020.

\section{Table 2}

\begin{tabular}{lccccc}
\multicolumn{6}{l}{ Regression Analyses for Agency Characteristics } \\
\multicolumn{1}{c}{ Variable } & B & $\begin{array}{c}\text { Standard } \\
\text { error }\end{array}$ & Wald t & Sig. & $\begin{array}{c}\text { Exp } \\
\text { (B) }\end{array}$ \\
\hline Agency size & 0.001 & 0.000 & 14.01 & $.000^{* * *}$ & 1.001 \\
Community policing focus & 0.226 & 0.034 & 44.91 & $.000^{* * *}$ & 1.254 \\
Website engagement & 0.247 & 0.033 & 54.88 & $.000^{* * *}$ & 1.280 \\
Social media use & 0.165 & 0.041 & 16.2 & $.000^{* * *}$ & 1.179 \\
RMS sophistication & 0.107 & 0.056 & 3.657 & .056 & 1.113 \\
Constant & -3.730 & 0.409 & 83.13 & $.000^{* * *}$ & 0.024 \\
\hline
\end{tabular}

$* p<.05 . * * p<.01 . * * * p<.001$

RQ5: How many PDs offer justifications for providing open crime maps?

The final phase of data collection explored the 586 agencies with crime maps available in 2020 in greater detail. Of them, 28 crime maps were found to no longer be available, resulting in a final sample of 558 agencies. Of the 558 agencies that provided crime maps during data collection in $2021,79.0 \%(n=441)$ offered no justification as to 
why they have made maps publicly accessible, and $11.5 \%(n=64)$ provided non-specific justifications.

Only $10.4 \%(n=58)$ of agencies with crime maps in 2021 were found to provide a specific justification(s). Using a qualitative approach, specific justifications were classified into themes. The proportion of agencies offering specific justifications by type is as follows: a) risk communication to improve awareness $(4.5 \% ; \mathrm{n}=25)$, b) risk communication for crime prevention $(4.7 \% ; \mathrm{n}=26), \mathrm{c})$ improving legitimacy through transparency $(1.8 \% ; \mathrm{n}=10), \mathrm{d})$ improving legitimacy through trust-building $(0.2 \% ; \mathrm{n}=$ $1)$, and e) collaboration between police and community members $(3.9 \% ; n=22)$. It is important to note that as agencies may have several purposes for providing crime maps, specific justifications are not mutually exclusive. We provide some examples of specific justifications by type below:

a. Risk Communication (Awareness) - According to the World Health Organization (WHO) (n.d.), the purpose of risk communication is two-pronged, the first being "to enable people at risk to make informed decisions." Therefore, agencies communicating risk through crime maps to improve awareness, must imply that their goal is to raise citizens' awareness of risks or to educate citizens about crime.

"This Crime Mapping System is merely a tool for citizens to be more aware of crime occurring where they work/live." (Montgomery Police Department, n.d.)

"CPD believes the map is a useful tool that can help raise awareness and encourage viewers to work cooperatively with law enforcement." (Chandler Police Department, n.d.) 
"To further community awareness and improve accessibility to police services occurring in the community, the City of Roanoke Police Department has merged geographic information systems technology with police records management data to facilitate user-friendly public accessibility." (Roanoke Police Department, n.d.)

"The intention of the Public Safety Incident interactive map is to enhance community awareness of public safety activity within the City of Naperville." (Naperville Police Department, n.d.)

b. Risk Communication (Crime Prevention) - The second purpose of risk communication as defined by the WHO (n.d.) is for the public to be able to protect themselves and their loved ones from the informed risks (i.e. crime). Therefore, agencies communicating risk for crime prevention, must imply that they are providing crime maps so that citizens can take precautions for themselves, their property, and/or their loved ones.

"We hope increased awareness will empower community members to more frequently report suspicious activity, to take measures to better protect property, and to have a deeper understanding of what GFPD does to serve and protect Great Falls every day." (Great Falls Police Department, n.d.)

"The new software provides an easy tool for anyone to access such data and, if necessary, take greater precaution to lock doors, remove valuables from plain sight and confirm authenticity of solicitors. It's another strategy to improve public safety in our community." (Greenwood Police Department, n.d.)

"This tool increases awareness and assists citizens in taking an active role in protecting themselves and improving safety in their neighborhoods and businesses." (Roseville Police Department, n.d.)

"Community Crime Map is an interactive public crime mapping system that allows us to share crime information with the community while helping to reduce crime, improve public safety and enhance neighborhood-police partnerships." (Lawrence Police Department, n.d.) 
c. Legitimacy (Transparency) - Past literature have suggested that police legitimacy can be enhanced by enabling transparency (Grimmelikhuijsen \& Meijer, 2015). As ubiquitous as a term to identify, transparency in policing nonetheless calls for "visibility combined with some standard of moral regulation that holds individuals or organizations to account.” (Brucato, 2015, p. 40) Therefore, agencies stating that they aim to be transparent with the public were identified as justifying crime map provision as a way to improve legitimacy through transparency.

"The Fargo Police Department has partnered with City Protect to provide a tool for crime prevention, community awareness, and data transparency.” (Fargo Police Department, n.d.)

"The Southfield Police Department has taken a progressive approach to transparency by making crime data available to the public through numerous channels." (Southfield Police Department, n.d.)

"With this new [crime mapping] tool we hope to increase transparency and further grow our partnership with the community." (Great Falls Police Department, n.d.)

"The goal of the information portal is to increase transparency and be an engaging website with vast audience appeal.” (Woodridge Police Department, n.d.)

d. Legitimacy (Trust) - Another way police might enhance legitimacy is through building trust. Mutual trust between police and their communities has shown to increase citizen reliance on police, cooperation during critical situations, and collaboration in solving communal issues (Jackson, 2015). Agencies that stated that their goal is to increase trust with community, increase public confidence in police, or improve police-community relations were classified into the current category. 
"The approach leverages crime analysis and statistics regarding incidents that occur in Wilmington, with tracking of data and trends in near realtime to provide the department with greater levels of accountability, focus and follow-up." (Wilmington Police Department, n.d.)

e. Collaboration - By openly sharing crime and policing-related information, agencies can strive for increased transparency and trust. This in turn increase the likelihood of collaborative crime reduction and prevention efforts (Jackson, 2015). In this category were agencies which clearly stated that they aim to gain public cooperation (e.g. in reporting crimes, benefit community crime prevention activities).

"With this new tool we hope to increase transparency and further grow our partnership with the community." (Great Falls Police Department, n.d.)

"CityProtect.com will prove particularly valuable to those in the community who want to stay informed about what is going on in their neighborhoods and empower residents to work with the police department to address neighborhood crime issues." (Mount Prospect Police Department, n.d.)

"CrimeMapping is just one more way that we can work together as a community to reduce crime in New Britain." (New Britain Police Department, n.d.)

"The Community Crime Map is just one more tool we can use to enhance our quality working relationship with the community we serve." (Rapid City Police Department, n.d.)

RQ6: How many agencies offer metadata along with their crime maps?

Regardless of whether or not agencies offer justification for providing crime maps, we evaluated the proportion of agencies with crime maps $(n=558)$ in 2021 . Less than $15 \%$ of the 558 agencies provided each of type of metadata, the two most common being update frequencies $(10.2 \% ; \mathrm{n}=57)$ and details of map maintenance $(13.8 \% ; \mathrm{n}=$ 77). Each of the remaining types of metadata were offered by less than $10 \%$ of agencies 
with crime maps in 2021. Please refer to Table 3 for complete results of the review and respective proportions of agencies providing each metadata type.

\section{Table 3}

Proportion of Agencies Providing Metadata

\begin{tabular}{|c|c|}
\hline Category & $\%$ of agencies \\
\hline \multicolumn{2}{|l|}{ Data generation } \\
\hline Type(s) of data mapped & 9.7 \\
\hline Exclusions from data source & 9.3 \\
\hline Reason(s) for exclusions & 5.9 \\
\hline Data source(s) & 4.1 \\
\hline Data source limitations & 1.1 \\
\hline \multicolumn{2}{|l|}{ Geocoding and offsets } \\
\hline Modifications of mapped locations & 9.3 \\
\hline Extent of offsets & 5.4 \\
\hline Reason(s) for modifications & 1.6 \\
\hline If recorded data underwent geocoding & 0.7 \\
\hline Record method of addresses & 0.5 \\
\hline Type(s) of data offset & 0.5 \\
\hline Type(s) of data geocoded & 0.4 \\
\hline Geocoding accuracy & 0.0 \\
\hline \multicolumn{2}{|l|}{ Metadata and map maintenance } \\
\hline Details of map maintenance & 13.8 \\
\hline Update frequencies & 10.2 \\
\hline Delays & 3.9 \\
\hline Data revisions & 1.3 \\
\hline Descriptions of subcategories & 0.9 \\
\hline Crosswalk documents & 0.0 \\
\hline \multicolumn{2}{|l|}{ Map type documentation } \\
\hline Available map type(s) & 1.1 \\
\hline Details on incident display & 0.2 \\
\hline Map creation decisions & 0.0 \\
\hline Caveats of map type & 0.0 \\
\hline
\end{tabular}

\section{Discussion}


Decades of publicly opposed yet continued US government operations caused the American public to become cynical and untrusting (Coglianese, 2009). When faced with recent incidents of police treatment towards disadvantaged, minority populations (Adams et al., 1999), the government was met with demands for increased transparency. Such concerns, accompanied by increased recognition of the role of trust and legitimacy in effectiveness of policing, led to initiatives that call for open data sharing of police with the public. Similar to how international police agencies have been publishing crime data for public viewing through their websites (Chainey \& Tompson, 2012; Tompson et al., 2015), police agencies in the US started providing open crime maps. Although literature has acknowledged the increasing popularity of crime maps due to improvements in GIS technology, access to mapping software, and easier access to the Internet (Wartell \& McEwen, 2001), there has been limited research concretely evaluating their prevalence, reasons behind why police provide them, and the amount of explanation associated with crime maps offered to the public by agencies.

This study first evaluated differences in PD website and crime map availability over time, prevalent map types, and popular map delivery sources. As hypothesized, PD website and crime maps availability increased between 2013 and 2020. Interestingly, we only accounted for interactive maps, while findings from the 2013 LEMAS survey consisted of both interactive and static crime maps. More agencies delivered crime maps through external hosts rather than internally, and three external mapping companies RaidsOnline/LexisNexis, CityProtect, and Crimemapping.com - were found to be the most popular among US PDs. The dot map was found to be the dominant crime map type 
for both externally and internally generated maps, followed by density maps and choropleth maps.

In addition, using variables extracted from the 2013 LEMAS survey, the study evaluated some agency characteristics that may be associated with delivery of crime maps. Characteristics such as size, community policing emphasis (Rosenbaum et al., 2011), and technological capacity (e.g. website engagement, social media use, and RMS sophistication) (Yavuz \& Welch, 2014) has been associated with agency website availability. Because crime maps are primarily delivered through websites, we extended this notion by hypothesizing these agency characteristics may also be associated with crime map availability. In testing five characteristics, all but one - RMS sophistication seemed to significantly increase the likelihood of agency map delivery.

Actions always have to be preceded by purpose, and it is important for agencies to carefully consider their objectives of providing mapped content to the public (Quinton, 2011). Therefore, it is necessary to understand the rationale behind crime maps provision. In identifying whether or not PDs offer any reason at all, only a small number were found to do so, with even fewer offering concrete, specific justifications. Similarly, findings from our metadata review conducted in the final phase of the study indicated that very few agencies provided explanations concerning the data used for the crime map, spatial referencing processes deployed, metadata and map maintenance processes, and presentation of the crime map itself.

The first strength is related to its actionability. A main trend that can be derived from the findings is that although an increasing number of agencies are delivering maps, why they are doing so remains unclear in most case. Even for those that stated specific 
reasons for delivering crime maps, the researcher doubts if map delivery sources (if external) and the map types delivered effectively serve their objectives. While most agencies may require more consideration on their part to evaluate their own objectives of providing crime maps, it cannot be argued that the public needs to be aware of their local police departments' actions and the purposes behind them. Therefore, agencies should strive towards offering justifications (if they do not already), confirm the map types and design delivered reflect said justifications (as also recommended by Wuschke et al., 2021), and supplement crime maps with information that will foster confidence in viewers towards both crime maps and the agencies delivering them alike. As contributions, future research can examine whether or not map types currently offered by agencies fulfill intended objectives effectively. In addition, studies can also attempt to qualitatively document the types of metadata viewers consider most beneficial in understanding and evaluating crime maps.

The second strength of the study lies in its relatability. The researcher is a foreigner from a country where police departments do not share policing-related data in any form, including crime maps. As an individual who only saw her first crime maps while studying in the US, viewing them gave rise to questions about the mapped content and the legitimacy of these maps. The researcher anticipates most crime maps viewers being similarly uncertain and unable to fully comprehend the mechanisms of map generation, maintenance, and delivery. Findings suggested an increasing number of agencies are providing crime maps. Few, however, offered justifications for doing so and even fewer provided relevant information needed to evaluate the legitimacy of these crime maps. It will be beneficial for agencies to begin offering such information so that 
viewing crime maps does not cause more uncertainty among viewers but, instead, help them better understand and have confidence in the data they are being presented. Not only will doing so improve open crime map delivery by PDs in the US, it can also be adopted as a guideline for other agencies within the country or even internationally planning to implement open crime map delivery in the future. For example, future research can contribute to new implementations of open crime map delivery by first identifying reasons behind why they wish to deliver maps to the public and evaluating whether or not it is feasible to do so in the local context (e.g. if a town typically experiences three to five criminal incidents over a year, delivering crime maps may not be a necessary practice). If it is, studies can identify best practices from broader cartographic fields to ensure the least communication gaps as possible and incorporate suggestions into guidelines that can be followed by agencies striving to implement open crime map delivery.

Despite the positive policy and practice implications the current study can have, it is important to note that study is not without its limitations. Firstly, due to the longknown unstable nature of the World Wide Web (Selberg \& Etzioni, 2000), the URLs of agency websites and crime maps can also be unstable, with some of them changing with each phase of data collection, and temporarily or even permanently removed. Adding to the instability was the outbreak of COVID-19 which hugely impacted the functioning of agencies, employee retention, and therefore maintenance of all physical and digital services they provide. For example, an agency that have been delivering crime maps all along suspended this service for a certain period that coincided with the time of data collection. Among the sample of 1,677 agencies, there may be several similar cases, 
which may result in an unknown proportion of agencies with crime maps coded as "not having crime maps" and not included in the analysis. Therefore, the researcher acknowledges inconsistencies may exist in data either due to uncontrollable situational factors or the general prospect of increasing website availability and/or crime maps in the future. Although it can be said with confidence that the study will serve as reference for future research investigating similar topic areas, complete reliance on the dataset used for the current study is not recommended. Instead, with every new research, a new round of data collection should be conducted to ensure maximum accuracy in the findings.

Secondly, the researcher generated a random subset of 250 agencies employing one to nine officers and another for those employing 10 to 24 for time-saving purposes, while retaining all available agencies with more than 25 sworn personnel. Doing so may have inflated the difference between larger agencies and smaller agencies delivering crime maps. Related to sample selection, the findings of the current study cannot be generalized to all local police departments in the US, as it only accounted for 1,677 of those that responded to the 2013 LEMAS survey. Furthermore, findings also do not represent crime map delivery trends across law enforcement agencies in the US, as sheriff's offices, state police agencies, and tribal police departments were excluded from the study sample.

The second limitation is related to inter-rate reliability. A second rater selected a random sample of 100 agencies to examine website and crime map availability, map delivery source, and whether or not the maps were working. Because analyses indicated substantial agreement between the two raters for the 100 agencies, the researcher can state with confidence that the data coded was fairly accurate. However, inter-rater 
reliability could not be explored for all 1,677 cases in the sample. Nor was the researcher able to establish inter-rater reliability for a number of variables, including agency justification and types of metadata offered. Therefore, future research is recommended to employ more than one researcher in coding data, as it will ensure higher accuracy during the data collection process and increase confidence in the findings.

Finally, the justification and metadata review were mostly subjective, generated without formal prior evaluations of input from crime map viewers. The study's educated assumptions were based on research that has shown different map types (Groff et al., 2005; Wuschke et al., 2021), mapping techniques (Wuschke et al., 2021), map delivery, and presentation factors (Wuschke et al., 2021) can influence public perceptions. Therefore, the researcher urges future studies to first conduct a formal investigation in order to generate a more diverse, reliable checklist regarding map viewer opinion. Based on current findings, upcoming studies are also recommended to consider more qualitative approaches in order to gain a deeper understanding of agency justifications and crime map metadata and identify explicit patterns that may exist within them. With decent confidence established, specific, qualitative findings should have positive policy implications such as developing a detailed framework of best practices in crime map generation, maintenance, and delivery that police agencies can reference.

\section{Conclusion}

The current study explored some basic statistics concerning the prevalence of crime maps, how they are delivered to the public, and dominant map types offered. In addition, the researcher explored a few agency characteristics which may be associated 
with their likelihood to provide open crime maps. Finally, whether or not agencies offered justifications for doing so and whether or not they provided metadata along with their crime maps were evaluated. All in all, the study identified some key areas in which communication gaps might exist in the practice of open crime map delivery. While acknowledging limitations may exist and improvements can be made, the researcher confidently states that the current study can serve as a reference for future research investigating open crime map delivery by US PDs. Finally, in addition to exploring some basic statistics related to open crime map delivery in the US, the current research aims to serve as a first step in two main aspects: 1. improving map delivery by police agencies in the US, and 2. identifying potential communication gaps that can be addressed by US PDs or international police agencies planning to implement crime map delivery in the future. 


\section{References}

Adams, K., Garner, J. H., Langan, P. A., Alpert, G. P., Greenfield, L. A., Maxwell, C. D., Dunham, R. G., Henriquez, M. A., Smith, S. K. (1999). Use of force by police: Overview of national and local data. U.S. Department of Justice.

https://www.ncjrs.gov/pdffiles1/nij/176330-1.pdf

Barkworth, J. M., \& Murphy, K. (2015). Procedural justice policing and citizen compliance behaviour: The importance of emotion. Psychology, Crime \& Law, 21(3), 254-273.

Bednarz, S. W., Acheson, G., \& Bednarz, R. S. (2006). Maps and map learning in social studies. Social Education, 70(7), 398-432.

Braga, A. A., Turchan, B. S., Papachristos, A. V., \& Hureau, D. M. (2019). Hot spots policing and crime reduction: An update of an ongoing systematic review and meta-analysis. Journal of Experimental Criminology, 15, 289-311.

Brantingham, P. J., \& Brantingham, P. L. (1984). Patterns in crime. Macmillan.

Brucato, B. (2015). The new transparency: police violence in the context of ubiquitous surveillance. Media and Communication, 3(3), 39-55.

Bureau of Justice Statistics. (n.d.). Local police. https://www.bjs.gov/index.cfm?ty=tp\&tid=71

Bureau of Justice Statistics. (n.d.). Sheriff's offices.

https://www.bjs.gov/index.cfm?ty=tp\&tid $=72$

Bureau of Justice Statistics. (n.d.). Tribal law enforcement. https://www.bjs.gov/index.cfm?ty=tp\&tid=75\#terms_def 
Cairo, A., \& Schlossberg, T. (2019). Those Hurricane Maps Don’t Mean What You Think They Mean. The New York Times. Retrieved from https://www.nytimes.com/interactive/2019/08/29/opinion/hurricane-dorianforecast-map.html?referringSource=articleShare

Caplan, R., Rosenblat, A., \& Boyd, D. (2015). Open data, the criminal justice system, and the police data initiative. Data and Civil Rights: A New Era of Policing and Justice, 1027.

Carter, J. G., \& Fox, B. (2019). Community policing and intelligence-led policing. Policing: An International Journal, 42(1), 43-58.

Chainey, S., \& Tompson, L. (2012). Engagement, empowerment and transparency: Publishing crime statistics using online crime mapping. Policing, 6(3), 228-239.

Chainey, S., Reid, S., \& Stuart, N. (2002). When is a hotspot a hotspot? A procedure for creating statistically robust hotspot maps of crime. Taylor \& Francis.

Chandler Police Department. (n.d.). Maps and statistics. https://www.chandlerpd.com/data/

Clark, R. (1995). Situational Crime Prevention. Crime and Justice, 19, 91-150.

Coglianese, C. (2009). The transparency president? The Obama administration and open government. Governance, 22(4), 529-544.

Cohen, L. E., \& Felson, M. (1979). Social change and crime rate trends: A routine activity approach. American Sociological Review, 44(4), 588-608.

Cohn, E. G. (1996). The citizen police academy: A recipe for improving policecommunity relations. Journal of Criminal Justice, 24(3), 265-271. 
Cortina, J. M. (1993). What is coefficient alpha? An examination of theory and applications. Journal of Applied Psychology, 78(1), 98.

Crampton, J.W. (2001). Maps as social constructions: Power, communication and visualization. Progress in Human Geography, 25(2), 235-252.

Crimemapping.com. (n.d.). About Crimemapping.com. https://www.crimemapping.com/about

Daalder, I. H., \& Lindsay, J. M. (2001, December 1). Nasty, brutish and long: America's war on terrorism. Brookings. https://www.brookings.edu/articles/nasty-brutishand-long-americas-war-on-terrorism/

Dai, M., He, W., Tian, X., Giraldi, A., \& Gu, F. (2017). Working with communities on social media: Varieties in the use of Facebook and Twitter by local police. Online Information Review, 41(6), 782-796.

Duval, E. (2001). Metadata standards: What, who \& why. Journal of Universal Computer Science, 7(7), 591-601.

Eck, J., Chainey, S., Cameron, J., \& Wilson, R. (2005). Mapping crime: Understanding hotspots. US Department of Justice, Office of Justice Programs, Bureau of Justice Statistics. https://discovery.ucl.ac.uk/id/eprint/11291/1/11291.pdf

Eikelboom, A., Martini, E., Ruiz, L., St. Pierre, A. D., \& Tejani, A. (2017). Public crime mapping in Canada: Interpreting RAIDS Online. Cartographica: The International Journal for Geographic Information and Geovisualization, 52(2), $108-115$. 
Environmental Systems Research Institute. (2020). What is geocoding?

https://desktop.arcgis.com/en/arcmap/latest/manage-data/geocoding/what-isgeocoding.htm

Fargo Police Department. (n.d.). Crime mapping. https://fargond.gov/citygovernment/departments/police/police-records-data/crime-mapping

Friedmann, R. R. (1992). Community policing: Comparative perspectives and prospects. St Martin’s Press Meredith Howard. https://www.ojp.gov/ncjrs/virtuallibrary/abstracts/community-policing-comparative-perspectives-and-prospects

Goldstein, H. (1987). Toward community-oriented policing: Potential, basic requirements, and threshold questions. Crime \& Delinquency, 33(1), 6-30.

Graham, M., \& Zook, M. (2011). Visualizing global cyberspaces: Mapping usergenerated placemarks. Journal of Urban Technology, 18(1), 115-132.

Great Falls Police Department. (n.d.). Police. https://greatfallsmt.net/police

Greenwood Police Department. (n.d.). Greenwood police department crime data. https://www.arcgis.com/apps/webappviewer/index.html?id=b36e18822d7246558 d847bce8722980c\&extent=-9601464.8804,4797857.1328,$9560704.835,4816431.3307,102100$

Grimmelikhuijsen, S. G., \& Meijer, A. J. (2015). Does Twitter increase perceived police legitimacy? Public Administration Review, 75(4), 598-607.

Groff, E. R., Kearley, B., Fogg, H., Beatty, P., Couture, H., \& Wartell, J. (2005). A randomized experimental study of sharing crime data with citizens: Do maps produce more fear? Journal of Experimental Criminology, 1(1), 87-115. 
Harries, K. D. (1995). Mapping crime: Principle and practice. US Department of Justice: Office of Justice Programs, Crime Mapping Research Center. https://www.google.com/books/edition/Mapping_Crime/EJLaAAAAMAAJ?hl=e $\mathrm{n} \& \mathrm{gbpv}=1 \& \mathrm{dq}=$ Mapping + crime $:+$ Principle + and + practice. $\& p g=\mathrm{PR} 3 \&$ printsec $=\mathrm{fr}$ ontcover

Hickman, M. J., \& Reaves, B. (2001). Community policing in local police departments, 1997 and 1999. US Department of Justice: Office of Justice Programs, Bureau of Justice Statistics. https://www.google.com/books/edition/Community_Policing_in_Local_Police_D epar/SZraAAAAMAAJ?hl=en \&gbpv=1\&dq=Community + policing + in + local + pol ice + departments, $+1997+$ and $+1999 . \& p g=$ PA12\&printsec $=$ frontcover

Jackson, B. A. (2015). Strengthening trust between police and the public in an era of increasing transparency. Arlington, VA: Rand Corporation.

Jones, M. A., \& De Guzman, M. C. (2011). E-policing: The value of police websites for citizen empowered participation. E-government website development: Future trends and strategic models (pp. 211-227). IGI Global.

Kansas City Police Department. (n.d.). Crime mapping. https://www.kcpd.org/crime/crime-mapping/

Kendi, I. X. (2017, July 2). The Civil Rights Act was a victory against racism. But racists also won. The Washington Post. https://www.washingtonpost.com/news/madeby-history/wp/2017/07/02/the-civil-rights-act-was-a-victory-against-racism-butracists-also-won/ 
Lavrakas, P. J., Rosenbaum, D. P., \& Kaminski, F. (1983). Transmitting information about crime and crime prevention to citizens: The Evanston newsletter quasiexperiment. Journal of Police Science and Administration, 11(4), 463-473.

Lawrence Police Department. (n.d.). Crime map. https://lawrenceks.org/police/crimemap/

LexisNexis Risk Solutions. (n.d.). Community Crime Map. https://communitycrimemap.com

Long Beach Police Department. (n.d.). Crime incident mapping application. http://www.longbeach.gov/police/crime-info/crime-incidents/

Maguire, E. R., \& Mastrofski, S. D. (2000). Patterns of community policing in the United States. Police Quarterly, 3(1), 4-45.

McHugh, M. L. (2012). Interrater reliability: The kappa statistic. Biochemia Medica, $22(3), 276-282$.

McMahon, R. (2002). Contested memory: The Vietnam war and American society, 1975-2001. Diplomatic History, 26(2), 159-184.

Mesquite Police Department. (n.d.). Crime map. https://www.cityofmesquite.com/1790/Crime-Map

Montgomery Police Department. (n.d.). Crime data. https://www.montgomeryal.gov/city-government/departments/police/can-youhelp-me/crime-data

Mount Prospect Police Department. (n.d.). Crime data mapping. https://www.mountprospect.org/departments/police-department/crime-reportsmapping-1302 
Murphy, K., \& Tyler, T. (2008). Procedural justice and compliance behaviour: The mediating role of emotions. European Journal of Social Psychology, 38(4), 652668.

Naperville Police Department. (n.d.). Naperville public safety incident map. http://gis.naperville.il.us/Html5Viewer/index.html?viewer=IncidentMap New Britain Police Department. (n.d.). Crime mapping. http://www.newbritainpolice.org/index.php/crimemapping

Nizich, M. P. (2012). Determining the usage patterns of an electronic records management system by a police agency. Proceedings of the Northeast Business \& Economics Association, 236-239.

Paulsen, D., \& LeBeau, J. (2012). Survey and evaluation of online crime mapping companies. US Department of Justice: Office of Justice Programs. https://www.ojp.gov/ncjrs/virtual-library/abstracts/survey-and-evaluation-onlinecrime-mapping-companies

Piotrowski, S. J., \& Van Ryzin, G. G. (2007). Citizen attitudes toward transparency in local government. The American Review of Public Administration, 37(3), 306323.

President's Task Force on 21st Century Policing. (2015). Final Report of the President's Task Force on 21st Century Policing. Washington, DC: Office of Community Oriented Policing Services.

Prince William County Police Department. (n.d.). Crime mapping. https://www.pwcgov.org/government/dept/police/Pages/crimemapping.aspx 
Quinton, P. (2011). The impact of information about crime and policing on public perceptions: The results of a randomised controlled trial. National Policing Improvement Agency. https://www.researchgate.net/profile/PaulQuinton/publication/267205260_The_Impact_of_Information_about_Crime_and_ Policing_on_Public_Perceptions_The_Results_of_a_Randomised_Controlled_Tri al/links/55b40a6908ae092e9653b46d/The-Impact-of-Information-about-Crimeand-Policing-on-Public-Perceptions-The-Results-of-a-Randomised-ControlledTrial.pdf

Raleigh Police Department. (n.d.). Raleigh online crime mapping. https://raleighnc.gov/safety/content/Police/Articles/OnlineCrimeMapping.html Rapid City Police Department. (n.d.). Community Crime Map helps keep Rapid City residents in the know about crime in their neighborhood. https://www.rcgov.org/news/community-crime-map-helps-keep-rapid-cityresidents-in-the-know-about-crime-in-their-neighborhood2197.html?highlight=WyJjcmltZSIsIm1hcCIsImNyaW11IG1hcCJd

Reaves, B. A. (2015). Local police departments, 2013: Equipment and technology. US Department of Justice: Office of Justice Programs, Bureau of Justice Statistics. https://www.bjs.gov/content/pub/pdf/lpd13et.pdf

Reaves, B. A., \& Hickman, M. J. (1998). Census of state and local law enforcement agencies, 2008. US Department of Justice: Office of Justice Programs. https://www.bjs.gov/content/pub/pdf/csllea04.pdf

Regoli, N. (2019, October 2). 13 major pros and cons of Mercator projection. ConnetUs. https://connectusfund.org/13-major-pros-and-cons-of-mercator-projection 
Roanoke Police Department. (n.d.). Crime mapping.

https://www.roanokeva.gov/334/Crime-Mapping

Rochester Police Department. (n.d.). Rochester PD Crime Map Link.

CityofRochester.gov. Retrieved April 1, 2021, from

https://www.cityofrochester.gov/crimemapping/. Screenshot by author.

Rosenbaum, D. P., Graziano, L. M., Stephens, C. D., \& Schuck, A. M. (2011).

Understanding community policing and legitimacy-seeking behavior in virtual reality: A national study of municipal police websites. Police Quarterly, 14(1), 25-47.

Roseville Police Department. (n.d.). Crime mapping. https://www.cityofroseville.com/2016/Crime-Mapping

Saint Petersburg Police Department. (n.d.) Saint Petersburg Crime Map Link.

Stat.StPete.org. Retrieved April 1, 2021, from https://stat.stpete.org/stories/s/StPetersburg-Police-Department/59bm-h3px/. Screenshot by author.

Schreiber, E. M. (1973). Opposition to the Vietnam War among American university students and faculty. The British Journal of Sociology, 24(3), 288-302.

Selberg, E., \& Etzioni, O. (2000). On the instability of web search engines. RIAO, 19, $223-235$.

Sheridan, C., Gelb, A., Marciano, C., \& Fagan, J. M. (2011). Misinterpretation of Weather Warnings.

https://scholar.google.com/scholar?hl=en\&as_sdt=0\%2C38\&q=weather+map + mi sinterpretation\&oq $=$ weather + map + misinterpreted 
Southfield Police Department. (n.d.). Police department: Welcome to the Southfield police department. https://www.cityofsouthfield.com/departments/policedepartment

Stiglitz, J. E., \& Wallsten, S. J. (1999). Public-private technology partnerships: Promises and pitfalls. American Behavioral Scientist, 43(3), 52-73.

Thurman, Q. C., \& Reisig, M. D. (1996). Community-oriented research in an era of community-oriented policing. American Behavioral Scientist, 39(5), 570-586.

Tompson, L., Johnson, S., Ashby, M., Perkins, C., \& Edwards, P. (2015). UK open source crime data: Accuracy and possibilities for research. Cartography and Geographic Information Science, 42(2), 97-111.

Tyler, T. R. (2003). Justice, legitimacy, and the effective rule of law. Crime and Justice, $30,283-327$.

UCSB Geography. (2018, July 2). Why is North always “up” on maps? https://geog.ucsb.edu/why-is-north-up-on-maps/

United States Department of Justice: Office of Justice Programs, Bureau of Justice Statistics. (2013). Law Enforcement Management and Administrative Statistics (LEMAS), 2013 (ICPSR 36164) [Data Set]. Ann Arbor, MI: Inter-university Consortium for Political and Social Research. https://doi.org/10.3886/ICPSR36164.v2

University of North Carolina at Chapel Hill. (2021). Officer expectations and duties. https://police.unc.edu/recruitment/officer-expectations-duties/ 
The National Trial Lawyers. (2020, July 27). The History of American Police Brutality. Retrieved from https://thenationaltriallawyers.org/2020/07/the-history-ofamerican-police-brutality/

Wartell, J., \& McEwen, J. T. (2001). Privacy in the information age: A guide for sharing crime maps and spatial data. National Institute of Justice. Retrieved from https://www.ncjrs.gov/txtfiles1/nij/188739.txt

Wilmington Police Department. (n.d.). Compstat reports and crime mapping. https://www.wilmingtonde.gov/government/public-safety/wilmington-policedepartment/compstat-reports

Woodridge Police Department. (n.d.). Woodridge police department information portal. https://www.woodridgeil.gov/my_government/police_department/police/informat ion_portal.php

World Health Organization. (n.d). General information on risk communication. https://www.who.int/riskcommunication/background/en/\#: :text=Risk\%20communication $\% 20$ refers $\% 20$ to \%20the,themselves\%20and\%20their\%20loved\%20ones.

Wuschke, K., Henning, K., \& Stewart, G. (2021). Dots versus density: the impact of crime mapping techniques on perception of safety, police performance and neighbourhood quality, Policing and Society. DOI:

$10.1080 / 10439463.2021 .1874950$

Wuschke, K., Henning, K., Stewart, G., \& Bonn, K. (2017, October 12). First impressions: Considering the impact of crime maps on public perceptions of 
safety. [Conference session] Geography Speaker Series, Portland State University, Portland, OR, United States.

Yavuz, N., \& Welch, E. W. (2014). Factors affecting openness of local government websites: Examining the differences across planning, finance and police departments. Government Information Quarterly, 31(4), 574-583.

Zhou, G., Lin, J., \& Zheng, W. (2012). A web-based geographical information system for crime mapping and decision support. 2012 International Conference on Computational Problem-Solving (ICCP), pp. 147-150. 


\section{Appendix A: Map Justification Review}

A. In February 2021, is the agency publicly accessible crime map(s) on their websites? If no, terminate and skip to metadata review.

Yes

No

B. Document the URL containing crime map(s) or their preceding link.

Fill-in text:

C. What type of justification does the agency offer for providing open crime maps?

Select 1, 2, or 3:

1. No justification (If selected, skip to metadata review).

2. Non-specific justification. If selected, please document text containing the nonspecific justification.

Fill-in text:

3. Specific justification. If selected, please choose one or more of the following and document corresponding texts.

a. Risk communication to improve awareness

Fill-in text:

b. Risk communication to prevent crime

Fill-in text:

c. Enhancing transparency

Fill-in text:

d. Increasing trust

Fill-in text:

e. Collaboration

Fill-in text:

\section{Appendix B: Metadata Review}

A. Does the agency's website (or linked website) map some type of public safety event or criminal justice data?

Yes

No (If 'no', terminate this review.)

B. Data Generation

1. Does the agency identify the specific type(s) of data being mapped (e.g., dispatch calls for service (CFS), officer-initiated calls, criminal incident reports, traffic accidents, EMS response, etc.)?

Yes

No 
2. Does the agency provide a basic explanation of their data source, including details on how these data are generated? For example, an agency providing access to dispatch CFS should note that this data is generated by reports to 911 by members of the public. Incidents that are excluded from the data source, like calls self-initiated by officers, should also be documented.

Yes

No

3. Does the agency identify key limitations associated with their given data source? For example, an agency providing access to dispatch CFS should note that not all CFS involve criminal activity, that some incidents may generate multiple calls, and that many incidents initially coded as criminal do not lead to an official criminal incident report.

Yes

No

4. Does the agency clearly identify whether or not data have been excluded from mapping? For example, some agencies may map all incidents from their data source, while others may intentionally withhold some incidents.

Yes

No

5. Does the agency document reasons as to why some incidents are not available for mapping (e.g. privacy of victims, sensitivity of crime, ongoing investigation)? Yes

No

\section{Geocoding and Offsets}

1. Does the agency identify whether or not the data mapped undergo geocoding?

Yes

No

2. Does the agency identify the types of data that undergo geocoding? For example, some agencies may choose to geocode incident starting location (where an incident may have started occurring), while others may do so for locations where the incident ended (where an incident may have been reported or discovered). Locations where a crime was reported may not necessarily be where it started occurring.

Yes

No

3. Does an agency identify how incident addresses are recorded? For example, agencies may record addresses to the exact reported location, block midpoint, the hundred block system (XY system), to the latitude and longitude etc.

Yes

No

4. Does the agency report a geocoding accuracy rate?

Yes

No 
5. Does the agency definitively state whether incident locations (e.g. dots) are, in any way, modified when presented on crime map?

Yes

No

6. Does the agency identify how they offset data (e.g. random, street block)?

Some agencies may map incidents, to the exact reported location, block midpoint, the hundred block system (XY system), to the latitude and longitude etc.

Yes

No

7. Does the agency state reasoning behind why a particular offset method was selected? For example, displaying locations at block midpoint preserves privacy of victims and still retains partial accuracy in relation to exact incident location.

Yes

No

8. Does the agency note whether all incidents or only certain types of incidents undergo offsets? For example, agencies may offset locations of incident types that are more sensitive in nature (e.g. sexual offenses).

Yes

No

D. Data and Map Maintenance

1. Does the agency provide explicit descriptions for each sub-category of data presented on their maps? For example, criminal offenses like simple assault, aggravated assault, non-negligent homicide, rape, robbery, etc. need to be explicitly defined for the end-user.

Yes

No

2. In cases of externally generated maps, does the agency provide crosswalk documents showing how their local incident categories compare to the vendor's list of items?

Yes

No

3. Agency provides supplemental information concerning map maintenance processes such as data transfers (e.g. timing), data recency, frequency of data updates etc?

Yes

No

4. Does the agency states the frequency at which the crime map or metadata is updated?

Yes

No

5. Does agency clarify whether delays exist in data uploading? For example, some agencies may state incidents that occurred within the past 7 days are not yet available on their crime maps.

Yes 
No

6. Does the agency discuss whether or not existing/old data or map is updated to account for revised incidents (e.g. reopened investigations)?

Yes

No

\section{E. Map Documentation}

1. Does the agency identify the types of map available (e.g. dot maps, density maps, kernel density maps, choropleth maps)?

Yes

No

2. Does the agency describe map creation decisions such as projection, scaling, other spatial references that could alter map display? For example, in providing kernal density maps, an agency should clarify how appropriate features and measurements (e.g. bandwidth or cell size) are determined as they result in changes in final map display.

\section{Yes}

No

3. Does the agency note the data limitations (i.e. caveats) associated with each map type? For example, because kernal density maps represent relativity in data, they may indicate crime in areas where there is none. Similarly, depending on the type of data displayed (e.g. the total number of incidents occured compared to the total number of burglaries occured), choropleth maps may not be suitable to display total values. Dot maps may sometimes obscure repeat incidents in the same location.

\section{Yes}

No

4. Does the agency clarify how incidents are displayed? For example, crime maps may simply display raw incident counts without considering other underlying factors (e.g. population differences, areas covered in a certain jurisdiction etc.).

Yes

No 